\title{
Experimental Study on Lightweight Precast Composite Slab of High-Titanium Heavy-Slag Concrete
}

\author{
Jinkun Sun $\mathbb{D}^{1,2}$ Rita Yi Man $\mathrm{Li}^{1,}{ }^{3}$ Nuttapong Jotikasthira, ${ }^{1} \mathrm{Kui} \mathrm{Li}^{2}$ and Liyun Zeng ${ }^{1,2}$ \\ ${ }^{1}$ Rattanakosin International College of Creative Entrepreneurship, Rajamangala University of Technology Rattanakosin, \\ Bangkok 10700, Thailand \\ ${ }^{2}$ Civil and Architectural Engineering Institute, Panzhihua University, Panzhihua 617000, China \\ ${ }^{3}$ Sustainable Real Estate Research Center, Hong Kong Shue Yan University, North Point 999077, Hong Kong \\ Correspondence should be addressed to Jinkun Sun; paxf66290838@163.com
}

Received 11 October 2020; Accepted 4 June 2021; Published 14 July 2021

Academic Editor: Xuemei Liu

Copyright (c) 2021 Jinkun Sun et al. This is an open access article distributed under the Creative Commons Attribution License, which permits unrestricted use, distribution, and reproduction in any medium, provided the original work is properly cited.

\begin{abstract}
Precast composite slabs are an essential component in concrete-prefabricated buildings. At present, there are problems such as overweightedness and imperfect test for quality and structural performance of the precast floors, leading to restriction in the development of prefabricated buildings. In this study, by using industrial solid-waste high-titanium heavy slag as coarse and fine aggregates, with fly ash and silica fume for the partial substitution of the cement, we developed a green lightweight precast composite slab of high-titanium heavy-slag concrete (LPCSHTHSC) after adding shale ceramite as the light aggregate. By selecting the weight and the strength of LPCSHTHSC as the technical control indexes, we performed an orthogonal test of lightweight proportions. Through a comprehensive analysis of the compressive strength, splitting tensile strength, density, and an economic consideration, the optimal proportion was determined as follows: water-to-binder ratio of 0.43 , mixing amount of the fly ash of $4 \%$, mixing amount of the silica fume of $8 \%$, mixing amount of the water-reducing agent of $0.5 \%$, sand ratio of $35 \%$, and cement at the strength grade of 42.5. Next, the bending performance test was conducted on LPCSHTHSC. According to the results, the LPCSHTHSC exhibited excellent mechanical performance, and its ultimate bearing capacity far exceeded the designed value. The ultimate bearing capacity calculated using the plastic hinge wire method differed slightly from the test value, suggesting the applicability of the proposed method to the calculation of the ultimate bearing capacity. Finally, the finite element analysis results of LPCSHTHSC were consistent with the actual bending mechanical performance test results, which proved both the accuracy and the reliability of the present finite element analysis based on the plastic damage constitutive model. The present study can provide an insightful theoretical and test foundation for the lightweight application of high-titanium heavy-slag concrete in other prefabricated components.
\end{abstract}

\section{Introduction}

In recent years, the government of China has proposed a new direction of industrialisation and published a series of policy measures for the development of prefabricated buildings $[1,2]$. Such movement is in line with the guidance of local governments, prefabricated buildings have become a hotspot in the construction industry. Nevertheless, heavyweight prefabricated parts have increased the difficulty in transportation, assembly, and overall structural performance of the prefabricated structures. Therefore, a lightweight design that satisfies the project specifications appears as a goal that demands a prompt solution.

Precast composite slabs are an essential part of concreteprefabricated buildings but these materials have many problems, including overweightedness and imperfect test methods of the quality and structural properties of the precast slabs. Yu et al. [3] studied the failure mode, stiffness, crack, and bearing capacity of single-seam dense reinforced concrete composite slabs. In Gaurav et al. [4] study, through static analysis, the actual bending stress of the composite under the action of nonuniform loads under isotropic 
conditions is determined. Fan et al. [5] carried out static monotone loading tests on steel-concrete composite slabs and analyzed the bearing capacity, stiffness, and crack development. Yousuf [6] studied the nonlinear dynamics of flexural stiffness of composite plates. Zhou et al. [7] carried out static loading tests on the combination form of precastpost cast concrete and strength grade of precast floor concrete as variables. Valerio et al. [8] studied the elasticity of an anisotropic composite plate when bending and torque were applied in the plane. Arasan et al. [9] used a simple model to calculate the dynamic equivalent parameters of three-layer Sandwich plates quickly to calculate the equivalent dynamic response. Ege et al. [10] studied the vibration characteristics of three-layer Sandwich composite plates in a wide frequency range. Hai et al. [11] studied the double lap composite joint combined with bolts and V-notched plates. Jiang et al. [12] studied the mechanical properties of slotshaped floor and ceramic concrete composite slab and the shear resistance of slot-shaped composite surface.

High-titanium heavy slag is a part of dense slag from blast-furnace slag that is produced in the smelting of vanadium titano-magnetite from Panzhihua steel via natural cooling or hot splashing, in which the content of $\mathrm{TiO}_{2}$ is as high as $22 \%$. Therefore, it is called high titanium heavy slag $[13,14]$. At present, because of the difficulty in the extraction of titanium and land occupation induced by bulk deposition, high-titanium heavy slag severely affects the environment. Previous research results have demonstrated that high-titanium heavy slag satisfies the requirements of building materials in terms of structural stability, crushing performance, durability, and radioactivity $[15,16]$. High-titanium heavy-slag concrete is prepared by replacing the natural stones and sands with the graded and crushed high-titanium heavy slag and using fine admixtures as part of the cement. According to the relevant research results [13, 17], heavytitanium heavy-slag concrete is superior to other ordinary concretes in terms of compressive strength, splitting strength, and the bond-anchoring strength with rebars. The seismic resistance of high-titanium heavy-slag high-strength concrete column is comparable to an ordinary-aggregate high-strength concrete column [18], whose nodes exhibit better ductility and energy-dissipating capacity than ordinary concrete nodes [19]. Accordingly, high-titanium heavyslag concrete exceeds ordinary concrete in terms of performance and is therefore appropriate to use as prefabricated concrete components. Precast composite slabs are an essential part of concrete-prefabricated buildings but exhibit many problems, including overweightedness and imperfect test methods of the quality and structural properties of the precast slabs. In this study, industrial solid-waste and hightitanium heavy slag were selected as the coarse and fine aggregates, respectively, and coal ash/silica fume was used to partially replace cement. Meanwhile, the light-aggregate shale ceramisite was added to prepare an environmentfriendly, lightweight, precast composite slab.

In view of the above, to boost the application of green recycled materials in prefabricated building composite slabs [20], in this study, industrial solid-waste high-titanium heavy slag was used to replace ordinary gravel coarse aggregate and sand fine aggregate. After the addition of shale ceramite as the light aggregate, fly ash and silica fume were used to replace partial cement to develop a green lightweight precast composite slab. By selecting the concrete weight and strength of LPCSHTHSC as according to the technical control indexes, we performed an orthogonal test on lightweight proportions of composite slab concrete. Through a comprehensive analysis of the compressive strength, splitting tensile strength, density, and economic index with the variance and range analysis method, the optimal concrete proportion of LPCSHTHSC was determined. Using the finite element theory, orthotropic plate theory, and plastic hinge theory, Huang [21] analyzed and tested the composite slab. In addition, this kind of concrete was used to fabricate full-size composite slabs, and bending strength test on LPCSHTHSC was carried out to study the cracking load of the new-type concrete composite slab. Moreover, the ultimate bearing capacity of LPCSHTHSC was calculated by the plastic hinge method. Finally, ABAQUS finite element analysis software was used for finite element simulation on LPCSHTHSC, and comparative analysis was made based on experimental data to further verify the accuracy and rationality of the research results. Ren and Xu [22] also used the concrete damage model to perform elastoplastic finite element analysis on the full-process mechanical performance of the composite slab.

This study makes full use of high-titanium heavy slag, an industrial solid waste, as the concrete coarse and fine aggregate of LPCSHTHSC, which represents a model of innovative application of green building materials [23]. The developed lightweight concrete composite slab exhibits good performance in both bending bearing capacity and cracking, which is a new type of concrete-prefabricated composite slab PC component worthy of promotion.

\section{LPCSHTHSC Proportioning Test}

\subsection{Test Materials and Specimen Preparation}

2.1.1. Test Materials. In the present test, high-titanium heavy-slag stones were selected as the main coarse aggregates of the lightweight concrete, shale ceramisite was added to the lose-weight aggregate, and high-titanium heavy-slag sand was used as the fine aggregate. PC42.5 composite Portland cement manufactured by Panzhihua Cement Plant; first-grade silica fume manufactured by Jinxiang Scientific and Technical Corporation; second-grade flash manufactured by Hengnuo Filter Material Company, Gongyi, China; and Q8081 balanced liquid polycarboxylic acid system highperformance water-reducing agent from Qinfen Building Materials Company were used as the raw materials in this study.

2.1.2. Specimen Preparation. Two lightweight high-titanium heavy-slag concrete slabs (LPCSHTHSC) of two different sizes $(150 \mathrm{~mm} \times 150 \mathrm{~mm} \times 150 \mathrm{~mm}$ and $150 \mathrm{~mm} \times 150 \mathrm{~mm} \times$ $300 \mathrm{~mm}$ ) were prepared according to the proportions given in Table 1 . After the curing for 7 days, 14 days, and 28 days, both 
TABLE 1: Orthogonal test table for concrete mixture ratios.

\begin{tabular}{lcccc}
\hline Test number & Water-to-glue ratio & Fly ash content (\%) & Silica fume content (\%) & Water-reducing agent dosage (\%) \\
\hline A1B1C1D1 & 0.41 & 5 & 2 & 0.2 \\
A1B2C2D2 & 0.41 & 10 & 4 & 0.3 \\
A1B3C3D3 & 0.41 & 15 & 6 & 0.4 \\
A1B4C4D4 & 0.41 & 20 & 8 & 0.5 \\
A2B1C2D3 & 0.43 & 5 & 4 & 0.4 \\
A2B2C1D4 & 0.43 & 10 & 2 & 0.5 \\
A2B3C4D1 & 0.43 & 15 & 8 & 0.2 \\
A2B4C3D2 & 0.43 & 20 & 6 & 0.3 \\
A3B1C3D4 & 0.45 & 5 & 6 & 0.5 \\
A3B2C4D3 & 0.45 & 10 & 8 & 0.4 \\
A3B3C1D2 & 0.45 & 15 & 2 & 0.3 \\
A3B4C2D1 & 0.45 & 20 & 4 & 0.2 \\
A4B2C4D2 & 0.47 & 5 & 8 & 0.3 \\
A4B2C3D1 & 0.47 & 10 & 6 & 0.2 \\
A4B3C2D4 & 0.47 & 15 & 4 & 0.5 \\
A4B4C1D3 & 0.47 & 20 & 2 & 0.4 \\
A1B1C1D1 & 0.41 & 5 & 2 & 0.2 \\
A1B2C2D2 & 0.41 & 10 & 4 & 0.3 \\
A1B3C3D3 & 0.41 & 15 & 6 & 0.4 \\
\hline
\end{tabular}

compressive strength and antisplitting strength tests were performed.

\subsection{Orthogonal Test of the Proportions of LPCSHTHSC.} According to the field investigation and practical experiences at a precast concrete construction site, the apparent density of the concrete should be reduced by more than $10 \%$. We found that the weight of the high-titanium slag rocks increased by approximately $200 \mathrm{~kg} / \mathrm{m}^{3}$ after infiltration. The addition of shale ceramisite lightweight aggregates could help to achieve the goal of weight reduction. Therefore, we first assumed that the apparent density of the concrete was $1800 \mathrm{~kg} / \mathrm{m}^{3}$. According to Design Specifications of Mixing Proportion for Ordinary Concretes [24], the water consumption of the concrete was $210 \mathrm{~kg} / \mathrm{m}^{3}$, the collapsibility ranged from $180 \mathrm{~mm}$ to $210 \mathrm{~mm}$, the sand ratio was $35 \%$, and the proportion of shale ceramisite in the coarse aggregates was $24.5 \%$. Moreover, the usages of the other components were determined.

The water-to-binder ratio, the mixing amount of fly ash, the mixing amount of silica fume, and the mixing amount of the water-reducing agent were selected as the four variables. Each variable was set at four different levels. Accordingly, four-factor three-level [25] orthogonal tests were performed for determining the main influencing factors and the optimal mixing proportion, as listed in Table 1.

2.3. Analysis of Orthogonal Test Results. Table 2 lists the measured compressive strengths, splitting strengths, and apparent densities of the concrete specimens.

2.3.1. Analysis of Present Test Results. According to the test results, as listed in Table 2, the effects of various factors and different levels of each factor on the concrete's different performance indexes were evaluated by comprehensively analyzing different mechanical and operating indexes. The test data were further analyzed via range analysis and variance analysis.

2.3.2. Range Analysis. The range analysis [26] results of the test data showed that the mixing amount of the fly ash had a significant effect on the early strength, while the water-tobinder ratio most significantly affected the 28-day strength. The amount of the water-reducing agent most significantly affected the 28-day splitting strength, while the water-tobinder ratio exhibited the slightest effect on the splitting strength. With respect to the effect on the concrete density, the mixing amount of the water-reducing agent ranked first, followed by the water-to-binder ratio and the mixing amount of silicon fume, while the mixing amount of fly ash imposed the slightest effect. The addition of a high-performance water-reducing agent could effectively reduce the water usage, thereby decreasing the concrete density and enhancing the concrete strength. The water-to-binder ratio and the high-performance water-reducing agent showed identical influencing mechanisms, as listed in Tables 3-5.

2.3.3. Variance Analysis. By analyzing the variance analysis results, we found that the mixing amount of fly ash most significantly affected the 7-day compressive strength of lightweight high-titanium heavy-slag concrete, while various factors exhibited no significant effects on the 14-day and 28day comprehensive strengths, as listed in Tables 6-8.

Conclusively, the optimal mixing proportion of the LPCSHTHSC was determined by analyzing the compressive strength index, the splitting strength index, the apparent density, and economic factors, as listed in Table 9. In contrast to ordinary concrete under identical design conditions (with a density of $2450 \mathrm{~kg} / \mathrm{m}^{3}$ ), the apparent density was reduced by $11.9 \%$, while the weight of each precast slab was effectively reduced by $74.78 \mathrm{~kg}$. 
TABLE 2: Orthogonal test results.

\begin{tabular}{|c|c|c|c|c|c|}
\hline $\begin{array}{l}\text { Numbering } \\
\text { parameter }\end{array}$ & $\begin{array}{c}\text { 28-day split } \\
\text { strength }(\mathrm{MPa})\end{array}$ & $\begin{array}{l}\text { 7-day compressive } \\
\text { strength (MPa) }\end{array}$ & $\begin{array}{l}\text { 14-day compressive } \\
\text { strength }(\mathrm{MPa})\end{array}$ & $\begin{array}{l}\text { 28-day compressive } \\
\text { strength }(\mathrm{MPa})\end{array}$ & $\begin{array}{c}\text { Apparent density } \\
\left(\mathrm{kg} / \mathrm{m}^{3}\right)\end{array}$ \\
\hline A1B1C1D1 & 12.83 & 30.21 & 35.24 & 35.67 & 2178.7 \\
\hline $\mathrm{A} 1 \mathrm{~B} 2 \mathrm{C} 2 \mathrm{D} 2$ & 9.34 & 23.03 & 28.8 & 35.55 & 2165.5 \\
\hline $\mathrm{A} 1 \mathrm{~B} 3 \mathrm{C} 3 \mathrm{D} 3$ & 8.27 & 23.09 & 29.3 & 36.81 & 2166.3 \\
\hline $\mathrm{A} 1 \mathrm{~B} 4 \mathrm{C} 4 \mathrm{D} 4$ & 9.31 & 20.27 & 29.24 & 44.35 & 2209.1 \\
\hline $\mathrm{A} 2 \mathrm{~B} 1 \mathrm{C} 2 \mathrm{D} 3$ & 9.03 & 25.53 & 34.65 & 37.76 & 2215.8 \\
\hline $\mathrm{A} 2 \mathrm{~B} 2 \mathrm{C} 1 \mathrm{D} 4$ & 10.81 & 28.59 & 31.71 & 43.34 & 2228.9 \\
\hline $\mathrm{A} 2 \mathrm{~B} 3 \mathrm{C} 4 \mathrm{D} 1$ & 10.29 & 23.58 & 30.48 & 36.91 & 2165.1 \\
\hline $\mathrm{A} 2 \mathrm{~B} 4 \mathrm{C} 3 \mathrm{D} 2$ & 8.79 & 17.43 & 28.09 & 34.43 & 2160.1 \\
\hline A3B1C3D4 & 10.87 & 21.22 & 25.92 & 33.82 & 2190.7 \\
\hline $\mathrm{A} 3 \mathrm{~B} 2 \mathrm{C} 4 \mathrm{D} 3$ & 8.6 & 27.33 & 35.07 & 43.16 & 2218.4 \\
\hline A3B3C1D2 & 9.67 & 24.72 & 27.98 & 43.26 & 2135.5 \\
\hline $\mathrm{A} 3 \mathrm{~B} 4 \mathrm{C} 2 \mathrm{D} 1$ & 9.43 & 20.27 & 24.63 & 29.94 & 2148.2 \\
\hline $\mathrm{A} 4 \mathrm{~B} 1 \mathrm{C} 4 \mathrm{D} 2$ & 9.78 & 21.15 & 25.41 & 30.76 & 1903.4 \\
\hline $\mathrm{A} 4 \mathrm{~B} 2 \mathrm{C} 3 \mathrm{D} 1$ & 11.06 & 21.87 & 26.64 & 32.58 & 2082.1 \\
\hline $\mathrm{A} 4 \mathrm{~B} 3 \mathrm{C} 2 \mathrm{D} 4$ & 5.94 & 27.05 & 28.35 & 34.45 & 2180.1 \\
\hline $\mathrm{A} 4 \mathrm{~B} 4 \mathrm{C} 1 \mathrm{D} 3$ & 8.23 & 17.95 & 22.85 & 30.56 & 2161.3 \\
\hline
\end{tabular}

TABLE 3: Range analysis of 7-day compressive strength of concrete.

\begin{tabular}{lcccc}
\hline Level & & & $\begin{array}{c}\text { Strength (MPa) } \\
\text { Different factors } \\
\text { Silica fume content (\%) }\end{array}$ & Water-reducing agent dosage (\%) \\
\hline 1 & Water-to-glue ratio & Fly ash content (\%) & 37.6 & 33.78 \\
2 & 38.10 & 34.50 & 34.43 & 36.23 \\
3 & 37.86 & 38.41 & 34.41 & 37.07 \\
4 & 37.55 & 37.86 & 38.80 & 38.74 \\
Range & 32.09 & 34.82 & 4.39 & 4.96 \\
\hline
\end{tabular}

TABLE 4: Range analysis of 14-day compressive strength of concrete.

\begin{tabular}{lcccc}
\hline Level & & \multicolumn{2}{c}{$\begin{array}{c}\text { Strength (MPa) } \\
\text { Different factors } \\
\end{array}$} & \multicolumn{3}{c}{$\begin{array}{c}\text { Silica fume content (\%) } \\
\text { Water-to-glue ratio }\end{array}$} & Fly ash content (\%) & 29.19 & Water-reducing agent (\%) \\
\hline 1 & 30.66 & 30.36 & 29.11 & 29.25 \\
2 & 29.58 & 30.06 & 27.49 & 27.57 \\
3 & 28.40 & 29.03 & 30.05 & 30.47 \\
4 & 25.81 & 26.20 & 2.56 & 28.56 \\
Range & 4.85 & 4.16 & 2.90 \\
\hline
\end{tabular}

TABLE 5: Range analysis of 28-day compressive strength of concrete.

\begin{tabular}{lcccc}
\hline Level & & $\begin{array}{c}\text { Strength (MPa) } \\
\text { Different factors } \\
\text { Silica fume content (\%) }\end{array}$ & Water-reducing agent dosage (\%) \\
\hline 1 & Water-to-glue ratio & Fly ash content (\%) & 37.96 & 33.78 \\
2 & 38.10 & 34.50 & 34.43 & 36.23 \\
3 & 37.86 & 38.41 & 34.41 & 37.07 \\
4 & 37.55 & 37.86 & 38.80 & 38.74 \\
Range & 32.09 & 34.82 & 4.39 & 4.96 \\
\hline
\end{tabular}


TABLE 6: Variance analysis of 7-day compressive strength of concrete.

\begin{tabular}{|c|c|c|c|c|c|}
\hline Source of variation & Quadratic sum & Degree of freedom & Mean square & $F$ value & $P$ value \\
\hline Water-to-glue ratio & 10.54 & 3 & 3.51 & 0.22 & 0.88 \\
\hline Fly ash & 102.04 & 3 & 34.01 & 3.94 & 0.04 \\
\hline Silica fume & 42.06 & 3 & 14.02 & 1.03 & 0.41 \\
\hline Water-reducing agent & 17.63 & 3 & 5.88 & 0.38 & 0.77 \\
\hline Variance of sum & 172.27 & $\begin{array}{c}12 \\
F 0.05(3,12)--3.49\end{array}$ & & & \\
\hline
\end{tabular}

TABLE 7: Variance analysis of 14-day compressive strength of concrete.

\begin{tabular}{lcccc}
\hline Source of variation & Quadratic sum & Degree of freedom & Mean square & $F$ value \\
\hline Water-to-glue ratio & 72.83 & 3 & 24.28 & 2.21 \\
Fly ash content & 47.78 & 3 & 15.93 & 0.14 \\
Silica fume & 14.39 & 3 & 4.80 & 0.35 \\
Water-reducing agent & 17.18 & 3 & 5.73 & 0.30 \\
Variance of sum & 152.18 & 12 & & 0.37 \\
& & $F 0.05(3,12)--3.49$ & \\
\hline
\end{tabular}

TABle 8: Variance analysis of 28-day compressive strength of concrete.

\begin{tabular}{|c|c|c|c|c|c|}
\hline Source of variation & Quadratic sum & Degree of freedom & Mean square & $F$ value & $P$ value \\
\hline Water-to-glue ratio & 102.77 & 3 & 34.26 & 1.70 & 0.22 \\
\hline Fly ash content & 53.21 & 3 & 17.74 & 0.73 & 0.55 \\
\hline Silica fume & 67.40 & 3 & 22.47 & 0.97 & 0.44 \\
\hline Water-reducing agent & 56.79 & 3 & 18.93 & 0.79 & 0.52 \\
\hline Variance of sum & 33.24 & $\begin{array}{c}12 \\
F 0.05(3,12)--3.49\end{array}$ & & & \\
\hline
\end{tabular}

TABLE 9: Design of the optimal mixing proportion of LPCSHTHSC.

\begin{tabular}{|c|c|c|c|c|c|c|}
\hline Water-to-glue ratio & Fly ash content (\%) & Silica fume content $(\%)$ & Water-reducing agent dosage (\%) & Water & Sand rate $(\%)$ & Cement \\
\hline 0.43 & 4 & 8 & 0.5 & 210 & 35 & 293.2 \\
\hline
\end{tabular}

The densities of water and cement are represented in kilograms per cubic meter.

\section{Bending Tests on LPCSHTHSC}

3.1. Test Objective. Next, bending tests were performed for investigating forces on carrying bars, distribution bars, and truss bars; fracture development and crack condition; ultimate bearing capacity on the components; and deflection change in the composite slab.

\subsection{Preparation of LPCSHTHSC}

3.2.1. Size and Reinforcement of Composite Slabs. According to Specifications of Truss-Reinforced Concrete Composite Slabs, the length, width, and thickness of the LPCSHTHSC were $2180 \mathrm{~mm}, 900 \mathrm{~mm}$, and $130 \mathrm{~mm}$, respectively; the thickness of the precast part was $60 \mathrm{~mm}$, the thickness of the cast part was $70 \mathrm{~mm}$, and the thickness of the reinforcement cover was $15 \mathrm{~mm}$. Figures 1 and 2 show the specimen size and the reinforcement.

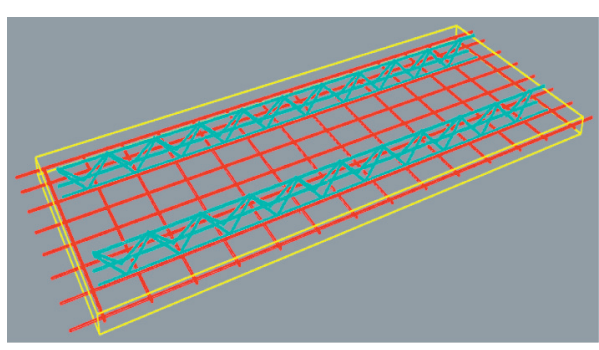

FIGURE 1: Illustration of LPCSHTHSC model.

3.2.2. Preparation of Composite-Slab Specimen. The composite slab was prepared in accordance with the National Building Standard Atlas (15G366-1) and certain local requirements. Firstly, the precast part was poured and placed in the curing tank for 28-day curing. Next, the concrete was poured. Finally, the specimen was covered by the insulating films for 28 days, and it underwent mechanical tests. 


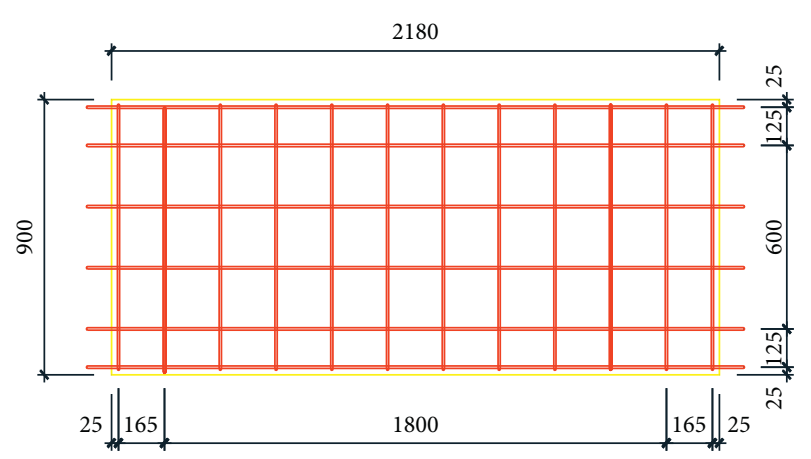

FIGURE 2: Illustration of the reinforcement of the composite slab.

Figures 3-5 show the preparation process of the composite slab.

3.3. Test Data Acquisition. Figures 6-8 show the arrangement of the positions of the strain gauges and the displacement meters. During the test, the appearance and development of the fractures, as well as the widths at each stage, were observed in detail. After the test ended, the test results were organised and analyzed for plotting the relative curve between the fraction deflection of the composite slab and the applied load.

3.4. Loading Test. The loading test was performed in accordance with the requirements in the specifications, the laboratory conditions, and the lightweight composite slab properties [27]. In order to achieve a uniform force transfer among the loading points, a thin layer of sand was paved above the composite slab. Figure 9 shows the loading device.

3.5. Static Loading Test Results of LPCSHTHSC and Data Analysis. Figures 10 and 11 show the bending fracture patterns of LPCSHTHSC under static loading.

3.5.1. Analysis of LPCSHTHSC Concrete Stress-Loading Test Results. Figures 12 and 13 show the stress/load curves of the LPCSHTHSC specimens.

According to the observational data during the test process (Figures 12 and 13), as the load increased from 0 to $17.5 \mathrm{kN}$, that is, the uniform loading rate reached $8.96 \mathrm{kN} /$ $\mathrm{m}^{2}$, the composite slab was in an elastic stage. As the load increased to $28.5 \mathrm{kN}$, microfractures appeared at the edge of the composite slab base. As the load increased to $42 \mathrm{kN}$, the concrete was under tensile stress, and fractures developed upwards along the short-span direction. The fractures gradually interconnected along the short-span direction with the increasing loading. As the load increased to $120 \mathrm{kN}$, the development rate of the interconnected fractures increased. As the load increased to $140 \mathrm{kN}$, the stress on the concrete in the compressive zone no longer increased, and the stress on the concrete in the tensile zone gradually approached 0 . At that moment, the maximum vertical fracture width at the main tensile reinforcement point and the composite slab underwent bending failure.

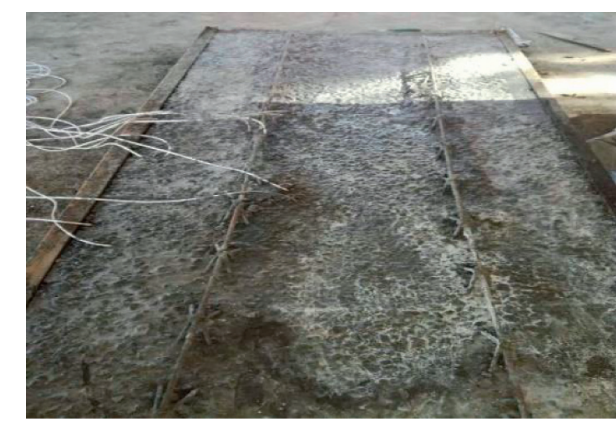

Figure 3: Preparation of LPCSHTHSC base plate.

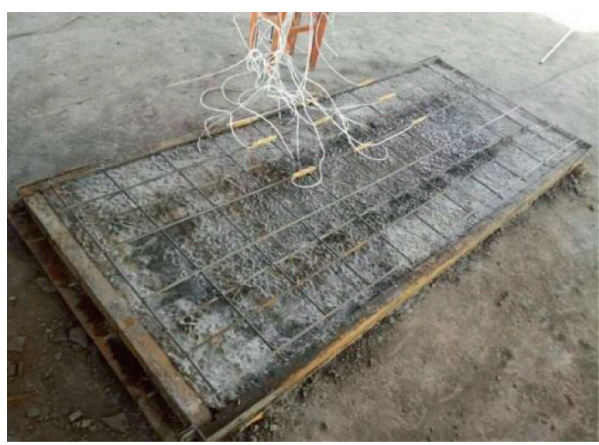

Figure 4: Reinforcement on LPCSHTHSC casting layer.

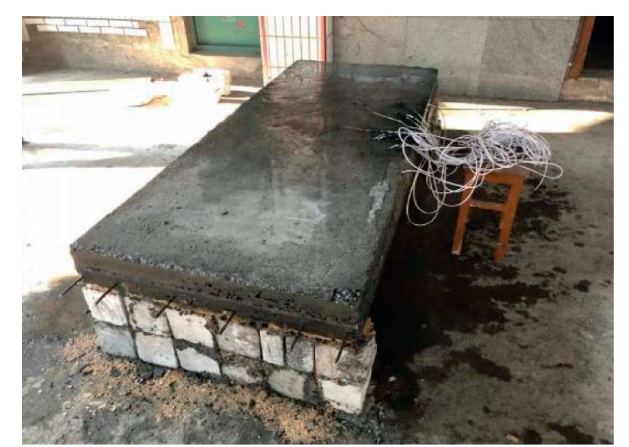

FIGURE 5: Photograph of the prepared LPCSHTHSC.

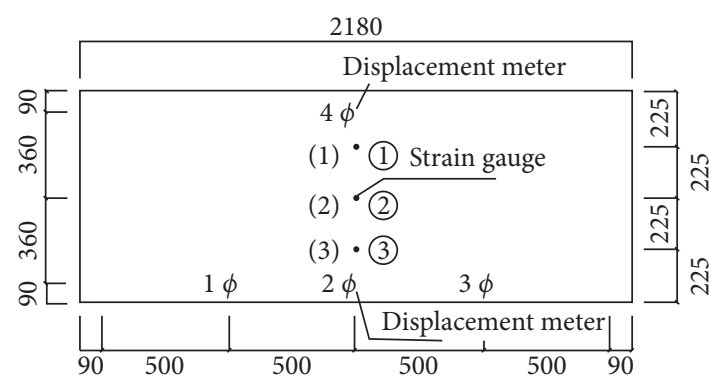

Figure 6: Plane arrangement of the strain gauges and the displacement meters.

3.5.2. Analysis of LPCSHTHSC Rebar Stress-Loading Test Results. Figures 14-16 show the stress/load curves of the LPCSHTHSC rebars. 


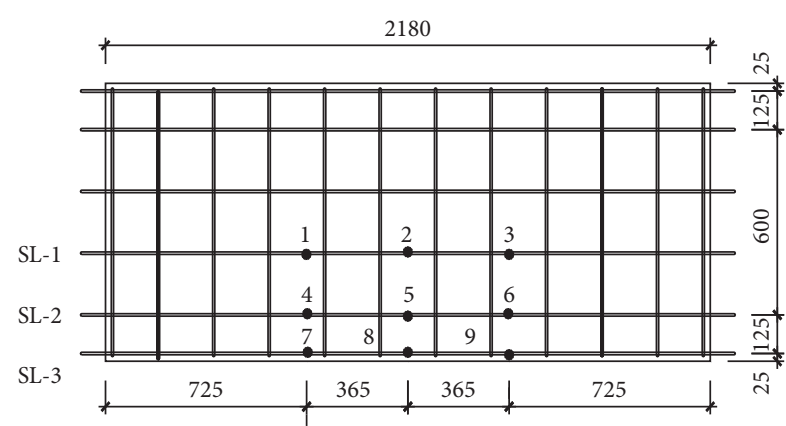

Figure 7: Arrangement plan of the strain gauge on the tensile bars on the composite base plate.

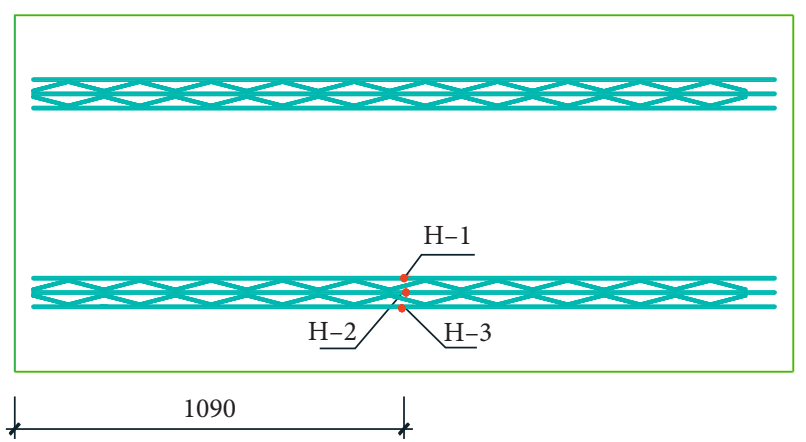

Figure 8: Arrangement of the strain gauges on the truss bar.

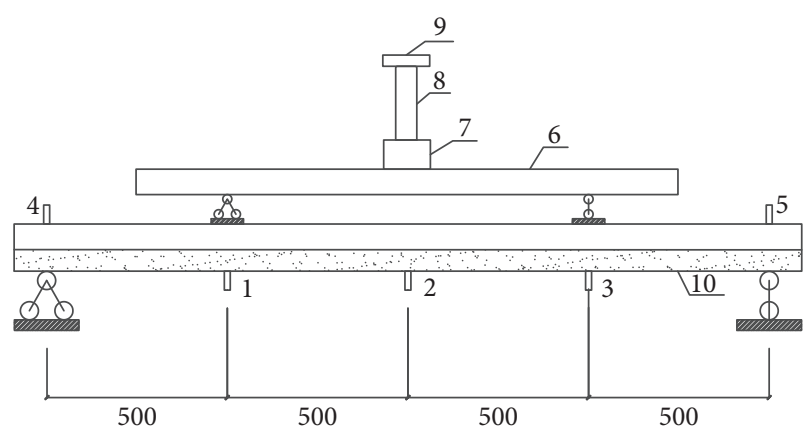

FIgURE 9: Plane arrangement of the loading device in the present test. (1-5) displacement meter; (6) distributive girder; (7) sensor; (8) jack; (9) counter-force rack; and (10) composite slab.

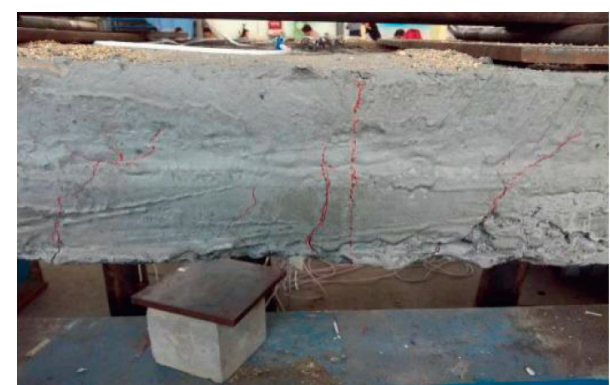

FIgURE 10: Fracture morphology at the edge of LPCSHTHSC specimen.

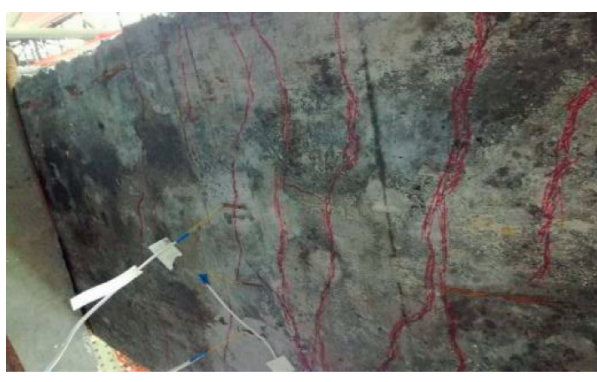

FIgURE 11: Interconnected fractures at the bottom of LPCSHTHSC.

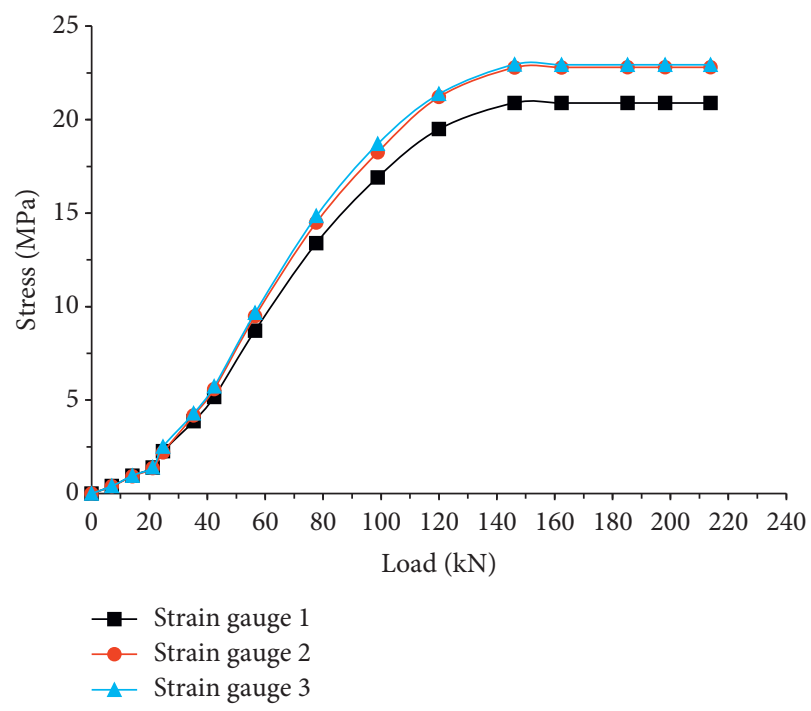

FIGURE 12: Stress/load curves at different measuring points in the compressive zone of the concrete specimen along the short-span direction.

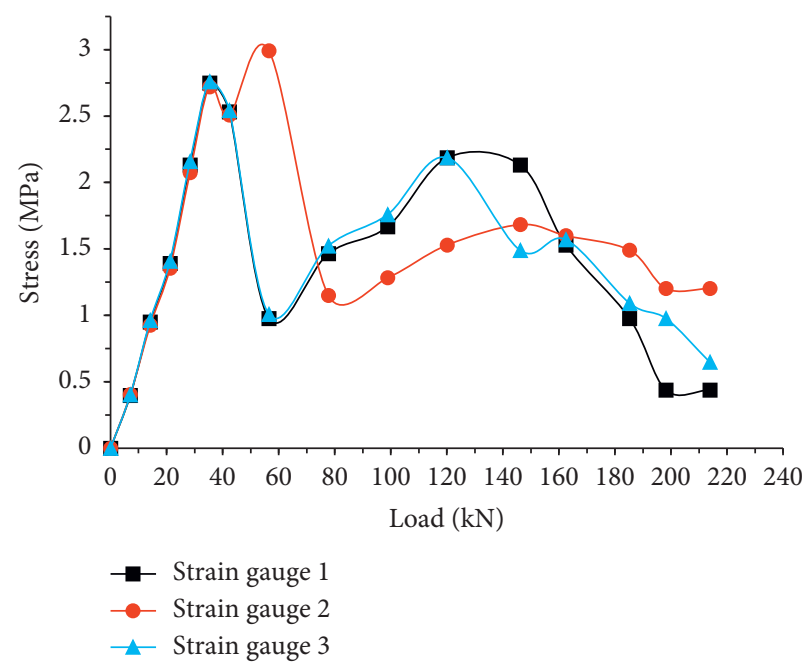

Figure 13: Stress/load curves at different measuring points in the tensile zone of the concrete specimen along the short-span direction. 


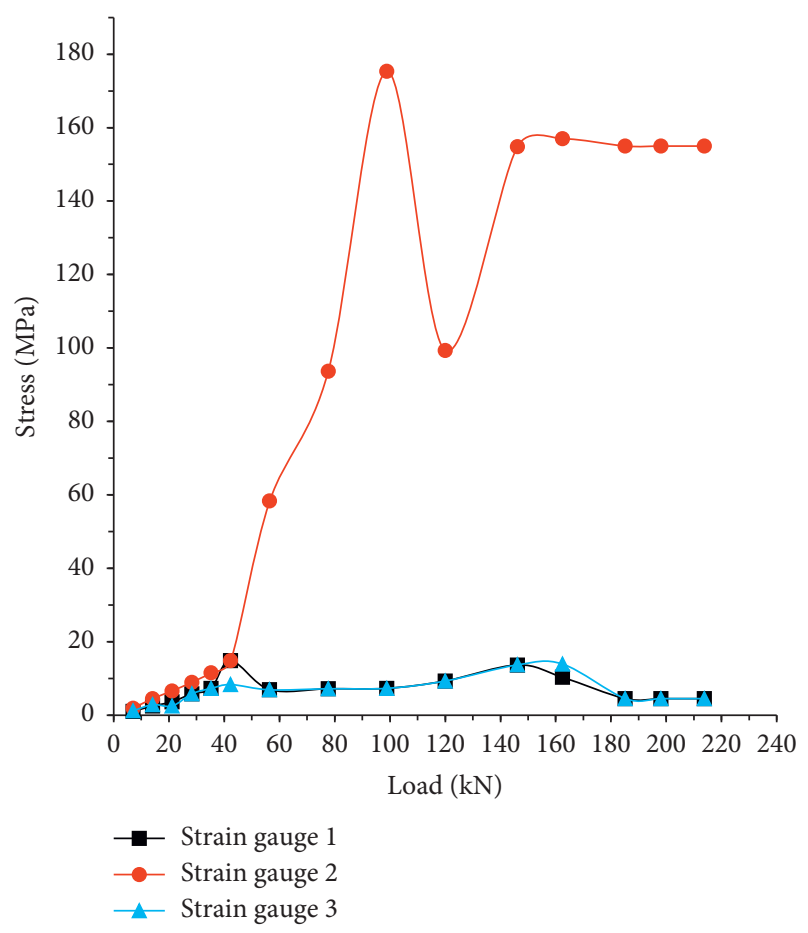

FIGURE 14: Stress/load curves at different measuring points on the SL-1 tensile LPCSHTHSC rebar.

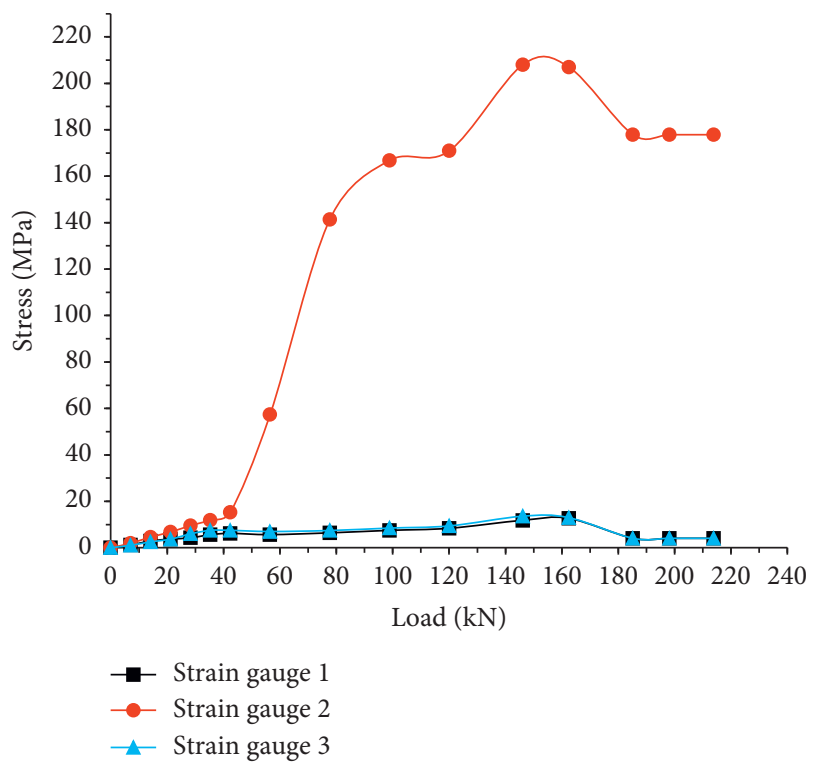

FIGURE 15: Stress/load curves at different measuring points on the SL-2 tensile LPCSHTHSC rebar.

As shown in Figures 14-16, before the vertical uniform load of $30 \mathrm{kN}$, the stress on the tensile LPCSHTHSC rebar linearly increased. As the load increased, the stress growth rate increased. Because the concrete in the compressive zone at the bottom of the composite slab cracked, the central axis moved upward, and the load on the concrete in the compressive zone was borne by the rebars in the tensile zone. Under a more massive load, the fractures at the bottom of

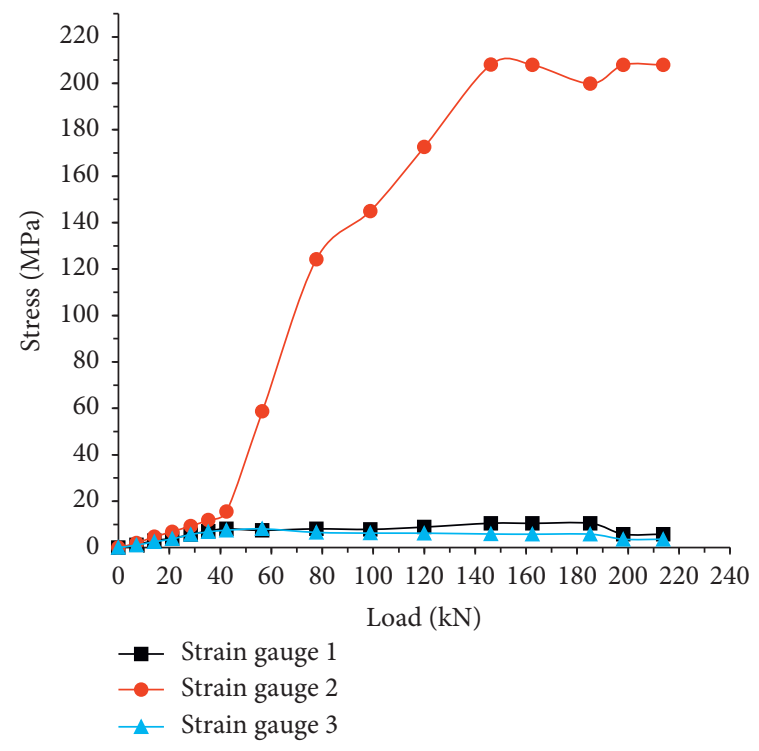

FIgURE 16: LPCSHTHSC SL-3 stress/load curves of tensile reinforcement at different measuring points.

the composite slab were higher, and the fractures developed at an increasing rate, thereby accelerating the stress growth on the rebars in the tensile zone. The fractures on the composite slab became wider under an increasing load, and the tensile force on the vertically tensile rebars at the slab bottom and the lower truss rebar increased steadily until they gradually yielded. Upon the failure of the composite slab structure, the component was unloaded until it became stable, and the deflection of the composite slab and the stress on the rebars no longer changed.

Figures 17 and 18 show the stress/load curves of different tensile rebars and truss bars along the short-span direction.

As shown in Figure 17, the stress on the midsection of the LPCSHTHSC rebar gradually dropped toward the two sides along the short-span direction. Because of the early appearance of fractures in the midspan of the composite slab, the stress on the midspan section of the tensile rebar abruptly increased. Since the fractures first appeared at the edge of the composite slab along the short-span direction, the stress on the marginal composite rebar rapidly increased. As shown in Figure 18, under the increasing load, the fractures at the bottom of the composite slab became wider, and the tension on the tensile rebar, particularly the stress on the midinterface rebars, increased. At that moment, the lower truss rebar gradually shared the load on the tensile rebar at the bottom. Therefore, the stress on the tensile rebar on the section centre suddenly dropped. As the stress on the lower truss rebar increased, the stress on the tensile rebar gradually recovered until failure. The stresses on the tensile rebar and the truss bar at the bottom tended to be stable.

Overall, the stress on the rebar net at the bottom was low before the appearance of fractures at the bottom of LPCSHTHSC. In addition, the stress and the applied load followed a particular linear relationship. After the fractures appeared at the bottom of the composite slab, the load became gradually shared by the rebar net rack at the bottom, 


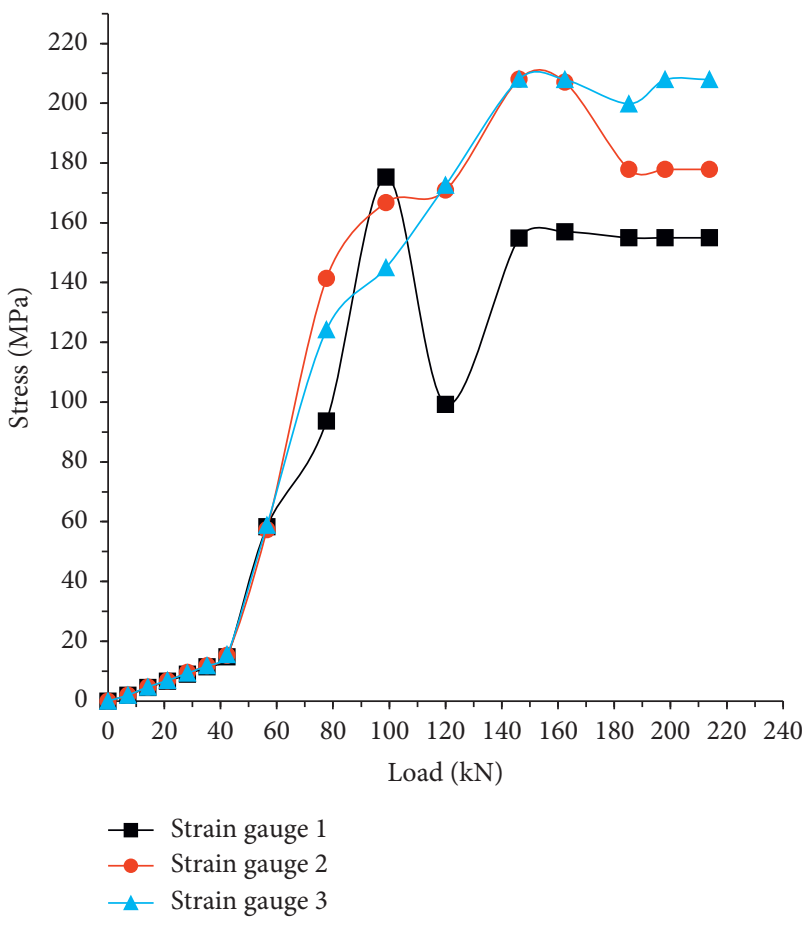

FIGURE 17: Stress/load curves of the LPCSHTHSC rebars in the midspan section along the short-span direction.

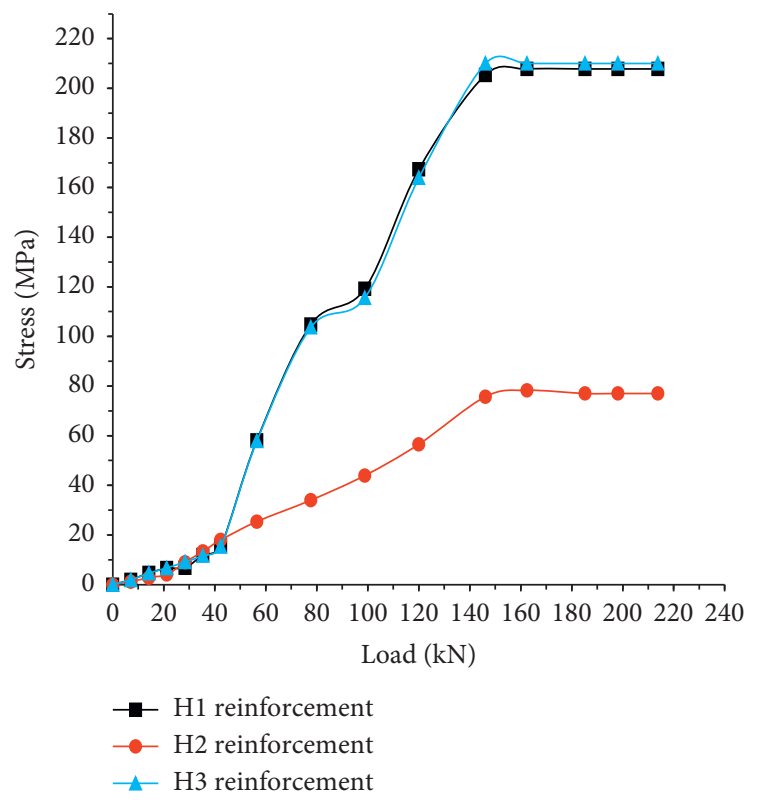

Figure 18: Stress/load curves of the LPCSHTHSC truss bars in the midspan section along the short-span direction.

thereby resulting in a rapid increase in the stress on the rebar. The lower truss bar could reinforce the longitudinal bar at the bottom. Accordingly, the stress on the top rebar was more significant.

\subsubsection{Analysis of Bearing Capacity on LPCSHTHSC}

(1) Calculation of Use Load. According to Design Specifications on the Concrete Structures [28], the load on the floor during the usage phase mainly included the live load on the floor, constant load on the components, and self-gravity of the floor. The additional constant load, the live load, and the unit weight of the floor concrete were set to $2.34 \mathrm{kN} / \mathrm{m}^{2}$, $2.0 \mathrm{kN} / \mathrm{m}^{2}$, and $21.5 \mathrm{kN} / \mathrm{m}^{2}$, respectively.

(2) Calculation of Design Load. The load on the slab under the permanent load control effect can be calculated as follows:

$$
Q=1.35 \times\left(G_{k_{1}}+G_{k_{2}}\right)+1.4 \times 0.7 Q_{k} .
$$

The load on the slab under the variable load control effect can be calculated as follows:

$$
Q=1.2 \times\left(G_{k_{1}}+G_{k_{2}}\right)+1.4 Q_{k},
$$

where $G_{k_{1}}$ denotes the self-weight of the floor, $G_{k_{2}}$ denotes the additional load, and $Q_{k}$ denotes the live load on the floor.

The design load was calculated to be $Q=8.96 \mathrm{kN} / \mathrm{m}^{2}$.

(3) Calculation of Cracking Load on Composite Slab. The cracking load on the composite slab can be calculated in accordance with Design Specifications on Concrete Structures [14] as follows:

$$
M_{c r}=\left(\sigma_{p c}+\gamma f_{t k}\right) W_{0},
$$

where $\gamma$ denotes the resistance moment plasticity influence coefficient of the concrete component section $(\gamma=1.55)$ and $f_{t k}$ denotes the axial tensile strength on the concrete $\left(f_{t k}=2.01 \mathrm{~N} / \mathrm{mm}^{2}\right)$. In this study, no prestressed bar was included in the composite layer $\sigma_{p c}=0$. Furthermore,

$$
W_{0}=\frac{b h^{2}}{6} .
$$

In this study, an LPCSHTHSC one-way slab was used. Under a uniformly distributed load $M_{c r}=1 / 8 q l^{2}$, the theoretical cracking uniformly distributed load was $q_{c r}=13.3 \mathrm{kN} / \mathrm{m}^{2}$. Therefore, the cracking load was calculated to be $F_{c r}=26.1 \mathrm{kN}$.

(4) Calculation of Ultimate Bearing Capacity of LPCSHTHSC. Because the composite slab was a doubly reinforced structure with a truss bar, the computing formula of the ultimate bearing capacity on the front rectangular section was no longer applicable to the model. In this study, we used a plastic hinge line method for the calculation. With this method, a failure mechanism coordinated with the boundary condition was assumed for the estimation of the ultimate bearing capacity [29]. The plastic hinge line method was initially proposed by Ingerslev and then improved and promoted by Johansen [30-32]. The existing test results demonstrated that the calculated ultimate bearing capacity based on the plastic hinge line theory was close to the test values. On the basis of the fundamental assumptions of determining the plastic hinge lines [33], the ultimate bending moment of the composite slab per unit width was calculated as follows [34]: 


$$
\begin{aligned}
& m_{x}=A_{s x} f_{s x} \gamma_{s x} h_{0 x}, \\
& m_{y}=A_{s y} f_{s y} \gamma_{s y} h_{0 y}, \\
& m_{x}^{\prime}=A_{s x}^{\prime} f_{s x}^{\prime} \gamma_{s x}^{\prime} h_{0 x}^{\prime}, \\
& m_{y}^{\prime}=A_{s y}^{\prime} f_{s y}^{\prime} \gamma_{s y}^{\prime} h_{0 y}^{\prime},
\end{aligned}
$$

where $A_{s x}$ and $A_{s y}$ represent the cross-sectional area of the longitudinal bar per unit width along the $l_{x}$ and $l_{y}$ directions on the slab, respectively; $f_{s x}$ and $f_{s y}$ represent the designed tensile strengths of the rebar on the slab section along the $l_{x}$ and $l_{y}$ directions, respectively; $l_{x}^{\prime}$ and $l_{y}^{\prime}$ represent the tensile strength of the rebar on the support section along the $l_{x}$ and $l_{y}$ directions, respectively; $\gamma_{s x}, \gamma_{s y}, \gamma_{s x}^{\prime}$, and $\gamma_{s y}^{\prime}$ are the internal lever arm coefficients (generally, $\left.\gamma_{s x}=\gamma_{s y}=\gamma_{s x}^{\prime}=\gamma_{s y}^{\prime}=0.9-0.95\right)$.

By taking into consideration the boundary condition of the composite slab, we could rewrite the ultimate bearing capacity and the forming position of the plastic hinge line as follows:

$$
\begin{aligned}
& s_{1}=\frac{\alpha \lambda_{1}}{2 n}\left(\sqrt{1+\left(\frac{3 n^{2}}{\alpha \lambda_{1}}\right)}-1\right), \\
& a_{q}=12 \times \frac{2 n+\left(\alpha / s_{1}\right)\left(1+\beta_{y}\right)}{3 n-2 s_{1}}, \\
& q=a_{q}\left(\frac{m_{x}}{l_{x}^{2}}\right),
\end{aligned}
$$

where $\lambda_{1}, \beta_{x}$, and $\beta_{y}$ are the position parameters of the plastic failure mechanism and were determined using the following formulas: $\lambda_{1}=1+\beta_{y}, \quad \beta_{x}=0, \quad \alpha=m_{y} / m_{x}$, $\beta_{x}=m_{x}^{\prime} / m_{x}$, and $\beta_{y}=m_{y}^{\prime} / m_{y}$. By substituting the above data into these formulas, we calculated it to be $q=76.55 \mathrm{kN} / \mathrm{m}^{2}$. Therefore, the ultimate bearing capacity on LPCSHTHSC was calculated to be $F=150.2 \mathrm{kN}$.

\section{(5) Test Results and Analysis}

(a) Comparative analysis of cracking load and ultimate load of LPCSHTHSC

(b) Analysis of deflection/load curve of the midspan of LPCSHTHSC

Figures 19 and 20 show the deflection/load relation curves at different positions on LPCSHTHSC.

As listed in Table 10, the measured cracking load was almost equal to the theoretical value, suggesting that the existence of the truss rebar had no effect on the cracking load of LPCSHTHSC. The error between the theoretical and the measured ultimate load was $3.2 \%$, which indicated that the plastic hinge line method was still applicable to the calculation of the ultimate load for the LPCSHTHSC unidirectional composite slabs.

Figure 19 shows that the deflections of the measuring points at two edges of the composite slab were almost equal to each other, which was indicative of the uniform stress on LPCSHTHSC. As shown in Figure 20, the deflection in the midspan of the composite slab was the most significant, which decreased gradually towards the two ends. By combining Figures 19 and 20, we concluded that the composite slab was fractured because the load was larger than $140 \mathrm{kN}$ (correspondingly, the maximum fracture in the midspan already exceeded $1.5 \mathrm{~mm}$ ); the loading process then stopped, and the deflection slowly dropped after reaching the maximum value during the unloading process and finally stabilised.

\section{Finite Element Analysis of Bending Mechanical Performance of LPCSHTHSC}

4.1. Selection of Finite Element Software. In this study, the ABAQUS finite element analysis software was selected for performing the finite element simulation on the composite slab. Further, the simulation results were compared with the test data for validating both the reliability and the reasonability of the present finite element analysis.

4.2. Establishment of Finite Element Model and Definition of Material Properties. For the convenience of model establishment and postprocessing, the geometrical models of the composite slab concrete, the truss rebar, and the rebar net were, respectively, established and then unified into a specimen, as shown in Figures 21-23.

After the geometrical models of various components were established, the corresponding properties were assigned to different materials. To be specific, the isotropic elastic/plastic model provided by ABAQUS was used for the finite element analysis of the rebars, and the concrete was described using the concrete damaged plasticity (CDP) model. The CDP model could combine the isotropic damaged elasticity, stretchability, and compressibility to express the concrete's nonelastic behaviours, in which two failure mechanisms, namely, tensile cracking and compressive failure, were assumed as the damage model, and the virtual damage plane in the stress space was used for determining whether the concrete cracked [35].

The constitutive model parameters in the CDP model included $\psi, \mu, \varepsilon$, uniaxial ultimate compressive strength ratio $f_{b_{0}} / f_{c_{0}}$, the tensile and compressive meridian plane second stress invariant ratio $k_{c}$, and the dilatancy angle $\varphi$. Overall, the parameter settings in the CDP model are listed in Table 11.

\subsection{Basic Assumption of the Model, Unit Selection, Mesh Generation, and Loading and Constraint Conditions}

4.3.1. Basic Assumption of the Model. In this study, we assumed that the composite slab concrete followed the small-deformation theory, while the effects of the shrinkage and the creep of the concrete in the precast composite layer and the poured layer were ignored. The deformation of the concrete was consistent with the deformation among the rebars [36].

4.3.2. Unit Selection and Mesh Generation. On the basis of the above analysis, in this study, we selected the separated 


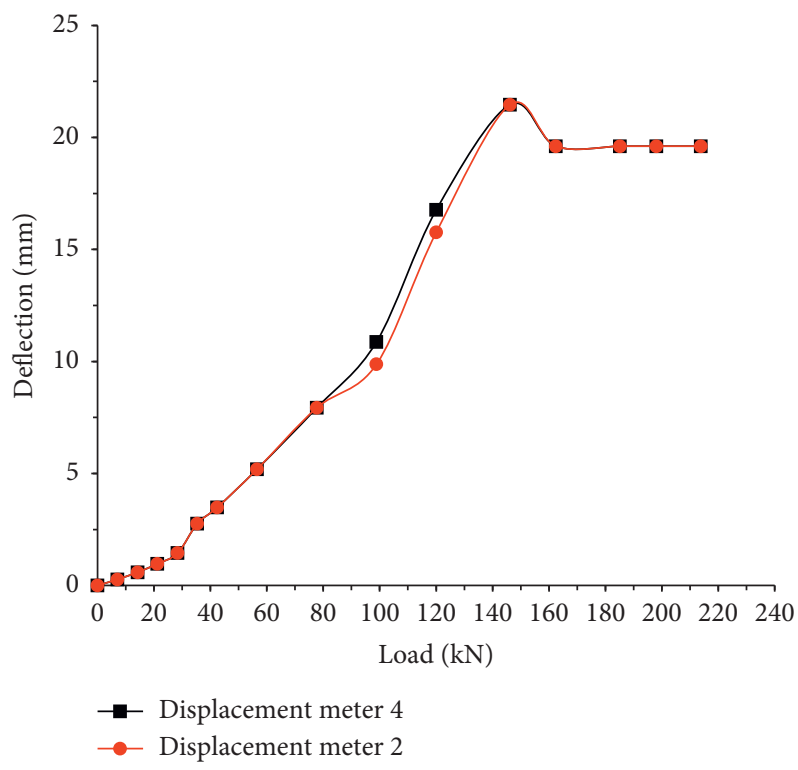

FIGURE 19: Deflection/load relation curves at different measuring points in the midspan of LPCSHTHSC along the short-span direction.

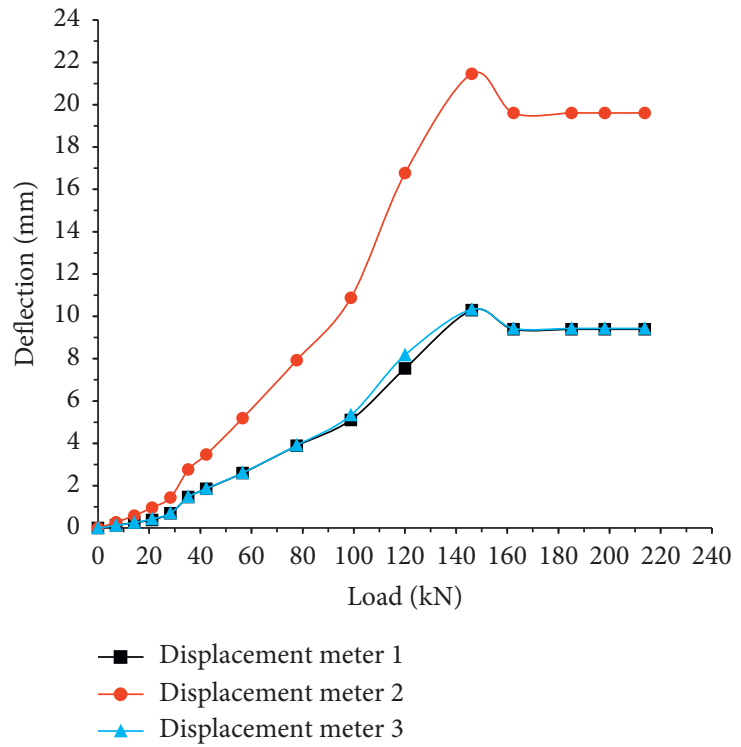

FIGURE 20: Deflection/load relation curves at different measuring points in the midspan of LPCSHTHSC along the long-span direction.

TABLE 10: Comparative analysis of cracking load and ultimate load of LPCSHTHSC.

\begin{tabular}{lccccc}
\hline \multirow{2}{*}{ Element type } & \multicolumn{2}{c}{ Cracking load $(\mathrm{kN})$} & \multicolumn{2}{c}{ Ultimate load (kN) } \\
& Theoretical value & Experimental value & Theoretical value & Experimental value \\
\hline Unidirectional composite slab & 26.1 & 28.5 & 150.2 & 145.5 \\
\hline
\end{tabular}

model and used various types of units to establish the models of the concrete and the rebar. In particular, the concrete and the rebar were simulated by $3 \mathrm{D}$ entities and truss units, in combination with the force characteristics of the composite slab model, the noncoordinated model unit (C3D8I), and the truss unit (T3D2). For the concrete unit and the rebar unit, the meshes with an identical size of $50 \mathrm{~mm}$ were adaptively generated [37]. Figure 24 shows the detailed mesh generation results.

4.3.3. Definitions of Load and Constraint in Finite Element Model of LPCSHTHSC. In this study, LPCSHTHSC used two-side fixed constraints that were consistent with actual 


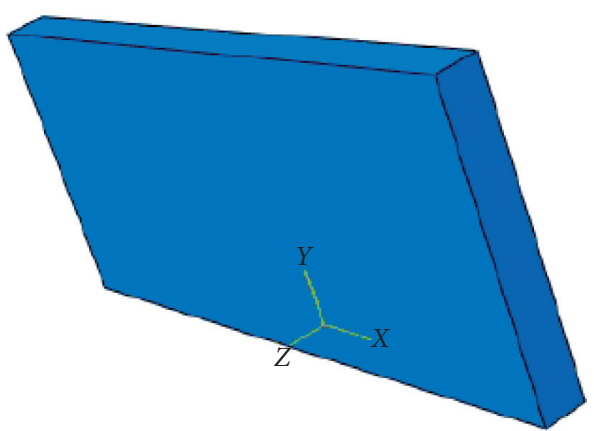

Figure 21: Model of the composite slab.

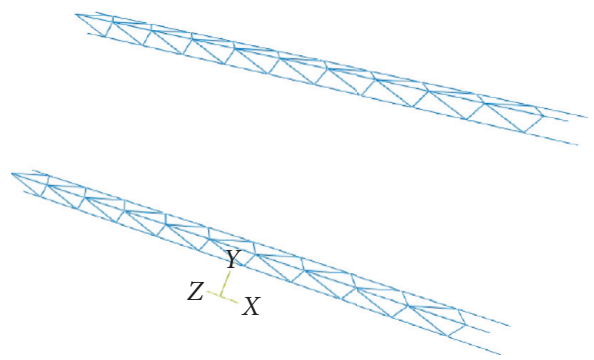

Figure 22: Model of the truss rebars.

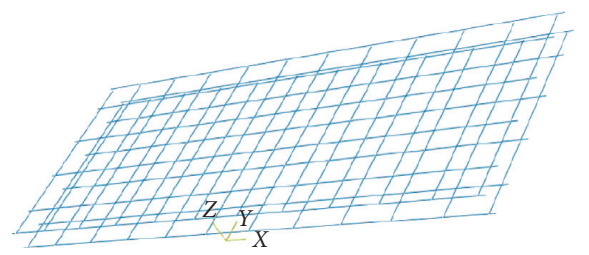

Figure 23: Model of the rebar net.

TABle 11: Parameter settings in concrete CDP model.

\begin{tabular}{ccccc}
\hline$\Psi$ & $\varepsilon$ & $f_{b_{0}} / f_{c_{0}}$ & $k_{c}$ & $\mu$ \\
\hline 30 & 0.1 & 1.15 & 0.6667 & 0.0005 \\
\hline
\end{tabular}

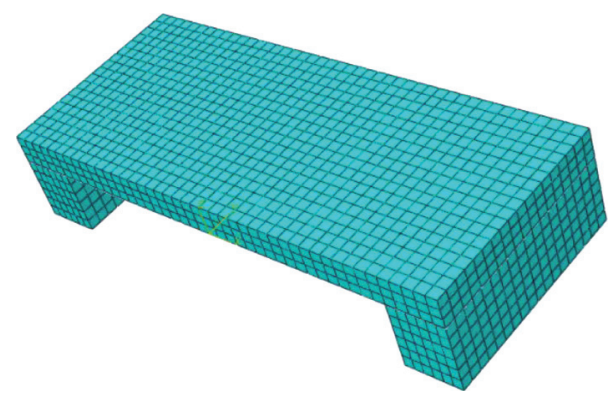

Figure 24: Meshed composite slab model.

engineering. Furthermore, to avoid the stress concentration on the ends and maintain consistency with the test conditions, concrete beams were added below the two ends of the composite slab. Moreover, to avoid the relative slip between the beam support and the truss rebar, tie constraints were used. The rebar net and the truss rebars were embedded into the entire concrete composite slab model for imposing the constraints. When dealing with the constraint on an old and a new concrete composite interface, because no relative slip appeared on the composite interface before the bending failure, we used the tie constraint model for neglecting the degrees of freedom of the contact surface and the relative slip [38]. Figure 25 shows the overall finite element model of LPCSHTHSC.

4.4. Analysis of Simulation Results of Bending Performance of LPCSHTHSC. In the surface loading control mode, the displacement, the stress, and the strain of the measuring point on the slab surface were extracted for plotting the deflection/load and stress/strain curves. The test model, as described in [39], and the related elastic-plastic parameters were selected for the present finite element analysis. Further, the finite element analysis results were compared with the test data for a contrastive analysis (Figures 26-38).

(1) Figures 26-28 show the cloud charts of the stress and the deformation on the slab concrete and the failure mode of the slab.

As shown in Figures 26, 27, and 29, the maximum stress and deflection positions appeared in the midspan of the composite slab. The maximum deflection was $16.52 \mathrm{~mm}$, which dropped steadily from the midspan toward the two ends. As the load increased from 0 to $30 \mathrm{kN}$, the composite slab was in the elastic stage, and the deflection linearly changed with the increasing load. As the load increased from $30 \mathrm{kN}$ to $60 \mathrm{kN}$, a turning point appeared on the curve, and several fractures appeared at the bottom of the composite slab; at this time, the stiffness began to drop, and the deflection changed at an increasing slope. The observations fit well with the test results, as shown in Figure 28, and the actual engineering data.

(2) Figures 30-34 show the cloud charts of the stress and the deformation of the rebars.

As shown in Figures 30-34, no fractures appeared on the composite slab with an increasing vertically uniformly distributed load of $30 \mathrm{kN}$, and the strain of the longitudinal rebar at the bottom was small. Before the uniform load of $30 \mathrm{kN}$, the stress/strain curve was almost linear. As the applied load increased, the strain increased at an increasing rate. With the widening of the fractures, the concrete in the tensile zone was gradually ineffective, and the stress was borne by the longitudinal tensile rebars at the bottom. Both the stress and the strain of the rebar in the midspan section were the greatest. As shown in Figures 33 and 34, a distinct turning point appeared in the stress/strain curve of the tensile rebar at the bottom of the composite slab. This was attributed to the fact that the composite slab was about 


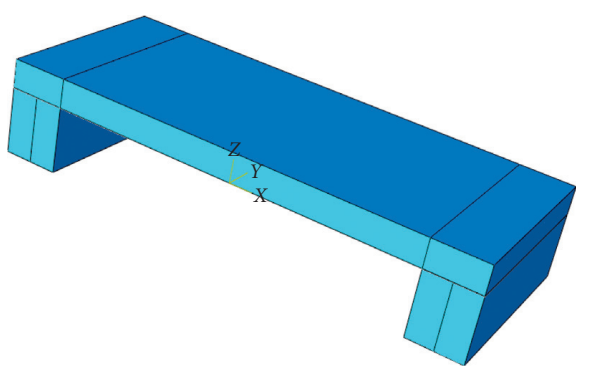

Figure 25: Overall finite element model of the composite slab.

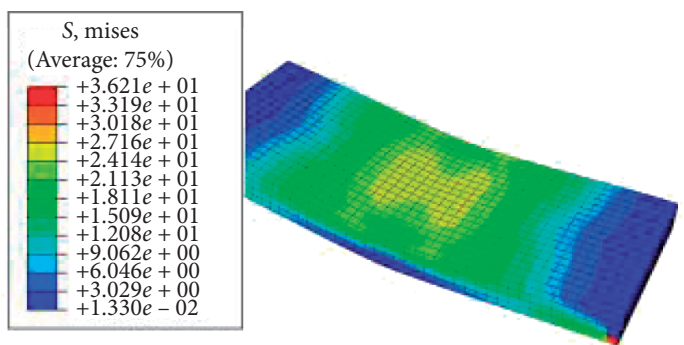

Figure 26: Stress cloud chart of the concrete under ultimate load.

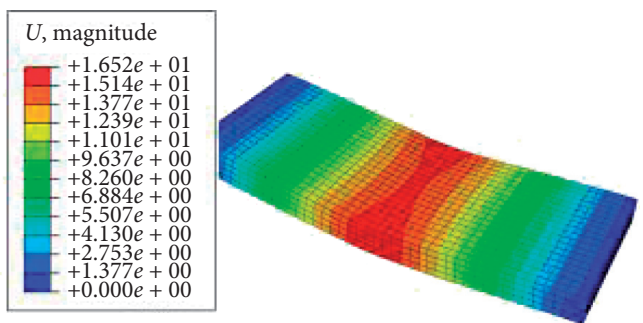

FIgURE 27: Deformation cloud chart of the concrete under ultimate load.

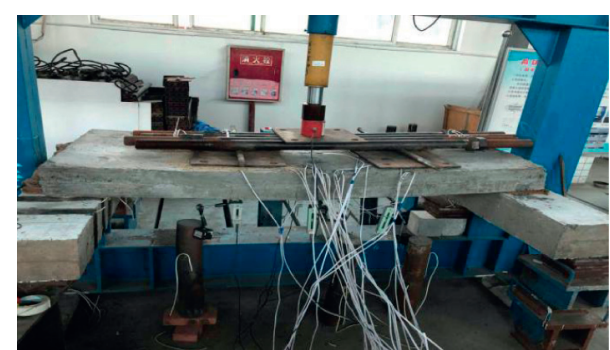

Figure 28: Failure mode of LPCSHTHSC under ultimate load.

to be destroyed. After the failure of the component, the stress on the longitudinal tensile rebar remained unchanged, but the stress increased until the load was slowly removed, and the composite slab tended to stabilise, as shown in Figures 29, 35, and 36.

As shown in Figures 18, 29, 35, and 36, the strain of the rebar increased under an increasing load. When the applied load dropped, the tension was shared by the concrete and the rebar. When the load was increased, the concrete cracked, and the tension on the
$S$, mises

(Average: $75 \%$ )

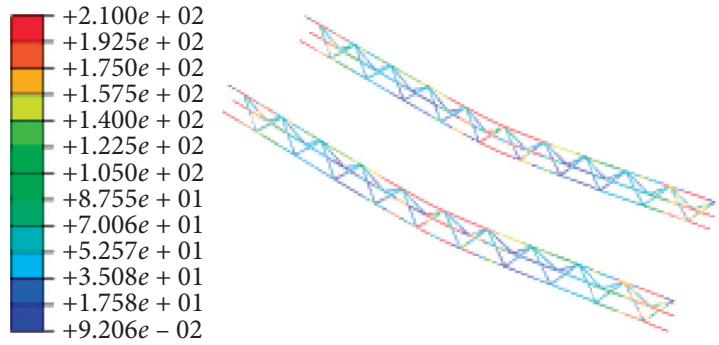

FIGURE 29: Cloud chart of the stress on the truss bar under ultimate load.

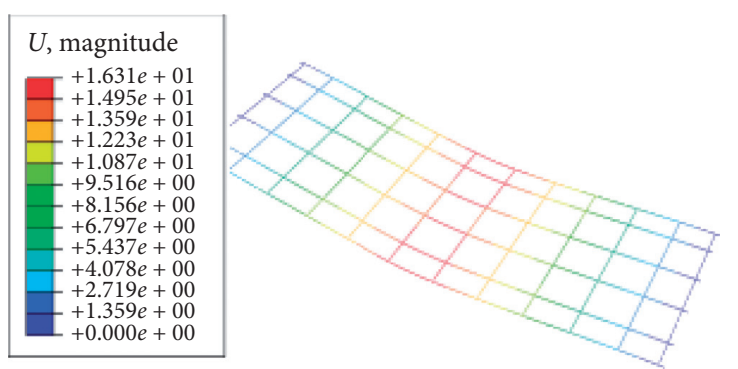

Figure 30: Cloud chart of the deformation of the rebar net under ultimate load.

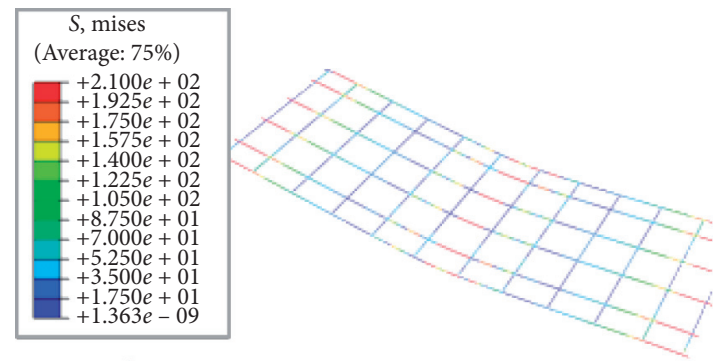

FIgURE 31: Cloud chart of the stress on the rebar net under ultimate load.

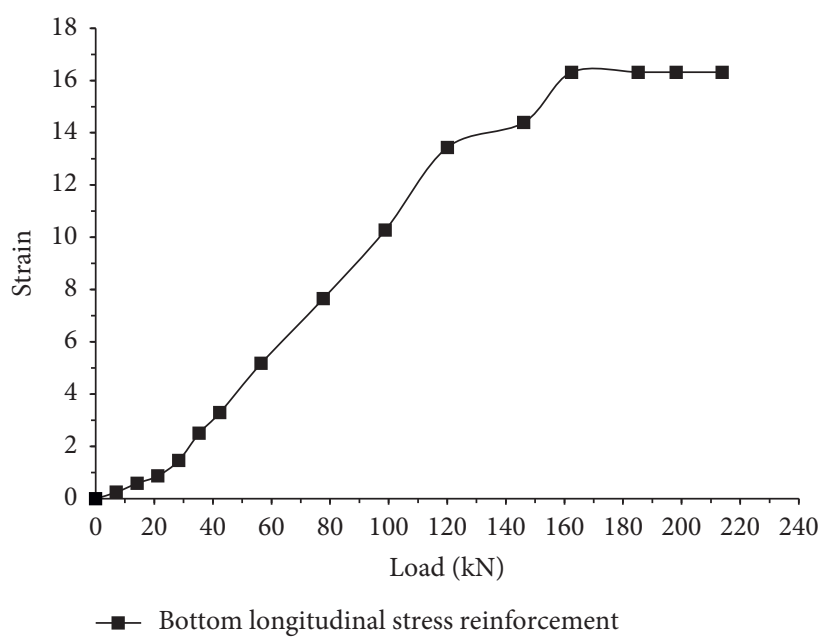

FIgURE 32: Deflection/curve relation curve of the midspan of the tensile rebar. 


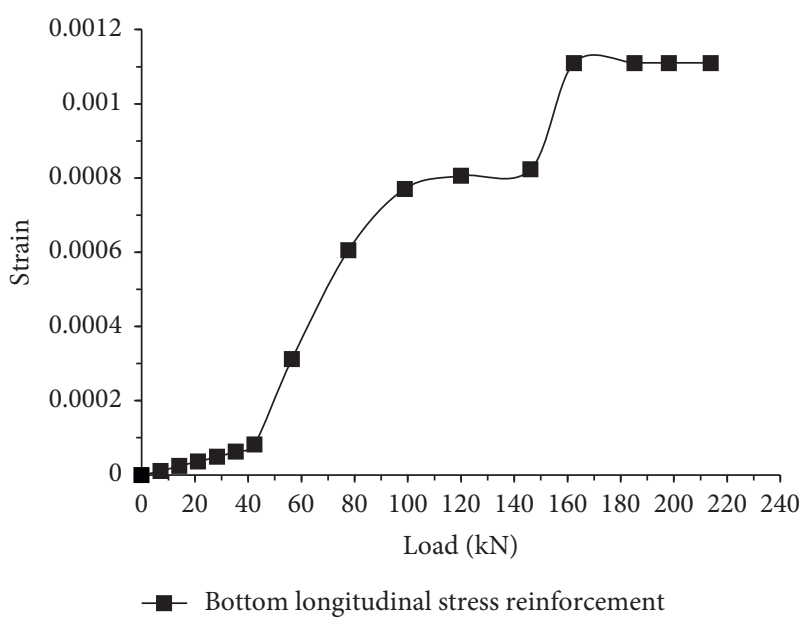

FIGURE 33: Stress/curve relation curve of the midspan of the tensile rebar.

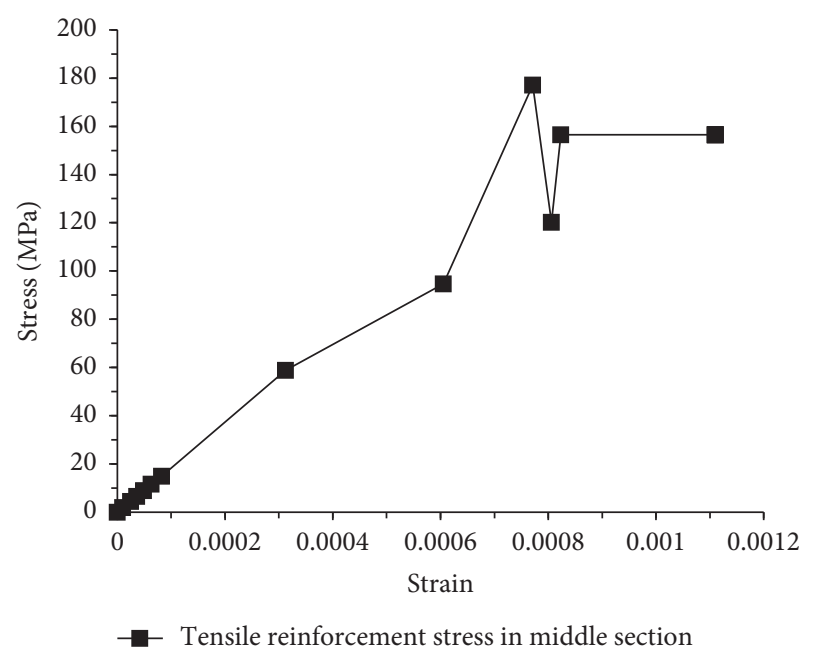

FIGURE 34: Stress/strain relation curve of the midspan of the tensile rebar.

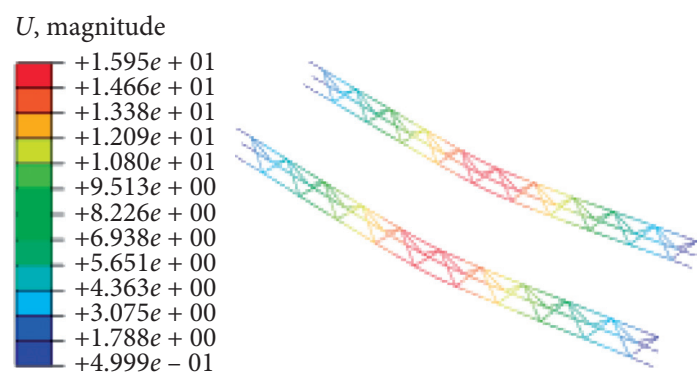

FIgURE 35: Cloud chart of the deformation of the truss bar under ultimate load.

concrete in the tensile zone was generated by the tensile longitudinal bars and the lower truss bars. As the stress increased to approximately $160 \mathrm{kN}$, the composite slab was fractured, and the loading process stopped. At this time, the strain of the tensile

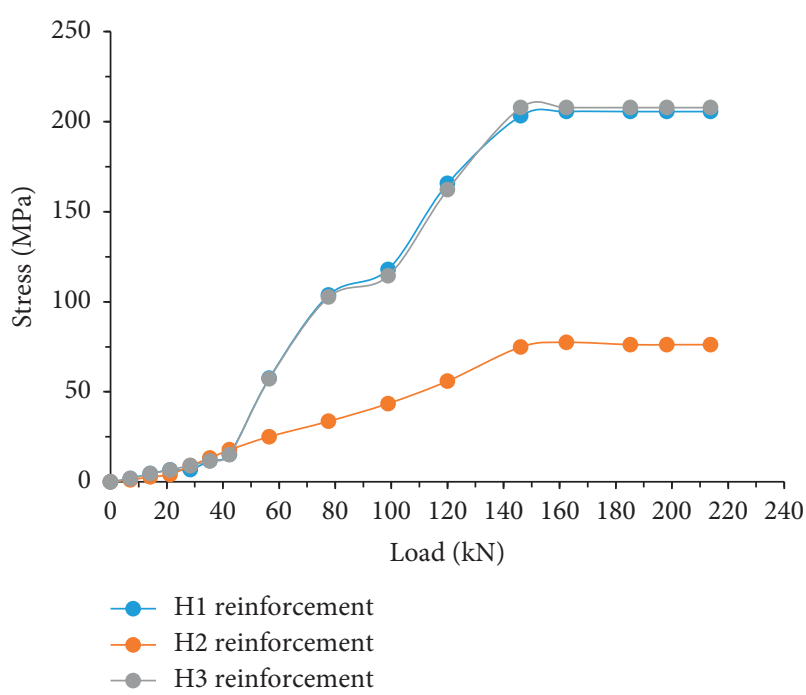

FIGURE 36: Strain/load curve of truss reinforcement.

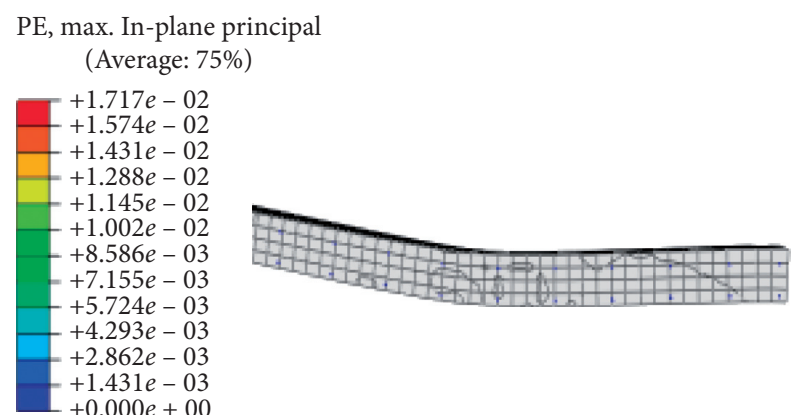

FIgURE 37: Cloud chart of the fractures on the composite slab along the long-span direction.

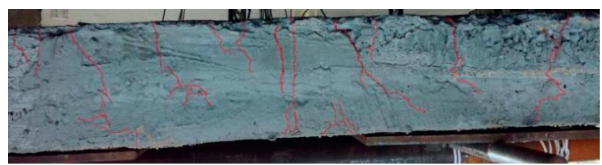

FIGURE 38: Fracture patterns on LPCSHTHSC along the long-span direction.

rebar reached up to 0.0011 , and the deflections of both the composite slab and the truss bar reached their maxima, as shown in Figures 27, 28, 30-34. The finite element analysis results were consistent with the test data.

(3) Figures 37 and 38 compare the fracturing pattern of the composite slab under the ultimate load.

Figures 37 and 38 show that the fractures that appeared in the present test were considerably similar to the simulated fractures on the failure surface, which confirmed the reasonability of the selected constitutive models of the rebar and the concrete. Moreover, the corrected plastic damage parameters were accurate. Therefore, the concrete 


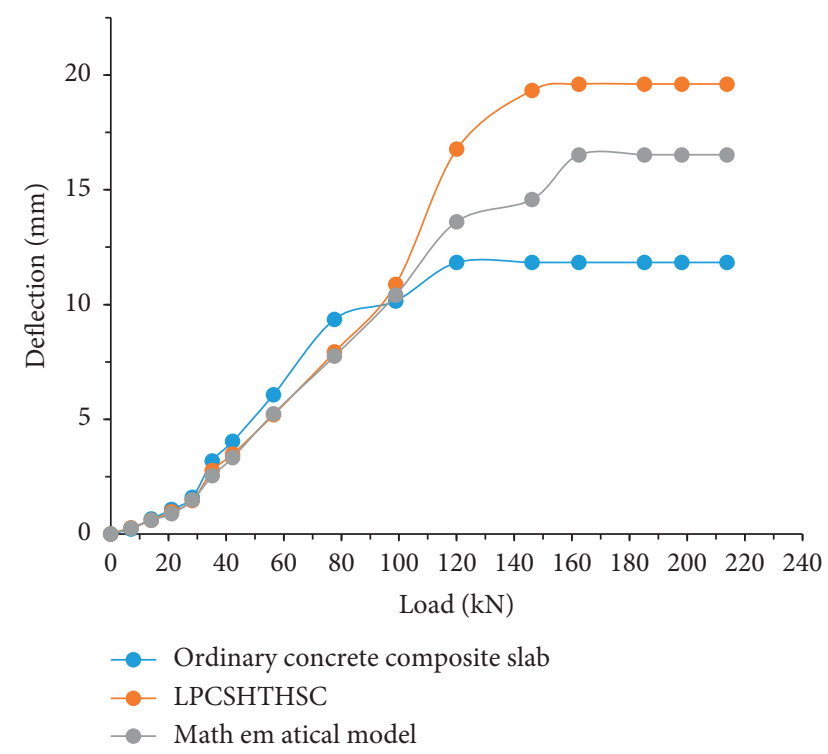

FIGURE 39: Comparison of deflection/load relation curves between traditional composite slab and LPCSHTHSC.

plastic damage model can be used for simulating the cracking behaviour of the novel LPCSHTHSC.

In combination with the existing conclusions [39], the modelling results of the composite slab consisting of ordinary concrete were compared with both the test data and the finite element simulation results of LPCSHTHSC, as shown in Figure 39.

Figure 39 shows the deflection/load curves of a traditional composite slab composed of ordinary concrete and the prepared LPCSHTHSC. Compared with LPCSHTHSC, the deflection of the traditional composite slab increased more rapidly, accompanied by a lower ultimate capacity. The growth rate of the deflection based on the mathematical model of LPCSHTHSC was consistent with the observation based on the present test model during the early stage. However, when the loading increased, the deflection growth rate based on the test model was significantly higher than that based on the finite element model. The ultimate bearing capacity of LPCSHTHSC calculated by the finite element model differed slightly from the test value.

\section{Conclusions}

In this study, through trial mixture based on orthogonal experiment, LPCSHTHSC concrete with the optimal mix proportion of C30 strength grade was created for LPCSHTHSC production. Based on the experimental and theoretical analysis, the formula for calculating the ultimate bearing capacity of such lightweight composite slab was derived. By simulating the entire force process of the composite slab using finite element analysis software ABAQUS [35], applicability of the optimized plastic damage model was verified. The following conclusions are drawn.

Through the experimental analysis on the mechanical properties of 16 groups of trial-mixed concretes, the following conclusions can be drawn:
(1) By adding shale ceramsite, superplasticizer, and other mineral admixtures under different waterbinder ratios of the trial-mixed concrete, we achieved the purpose of lightweight LPCSHTHSC concrete, and the compressive strength and splitting strength are superior to those of ordinary concrete under the same design strength.

(2) Through range analysis and variance analysis on the experimental data of the compressive strength and splitting strength of the trial-mixed concrete [26], we can conclude that the main factor that affected the concrete splitting strength was water-reducing agent, whose effect was the most significant; for the concrete compressive strength, the influencing factors change with the age, but the most significant factor affecting the early strength of concrete was admixture amount of fly ash.

(3) The variance analysis on the orthogonal test results of the trial-mixed concrete reveals that fly ash has significant effect on the compressive strength of concrete.

Based on concrete analysis on the influence of changes in different levels of various variable and factors on the compressive strength, splitting strength, and density of LPCSHTHSC concrete, the following conclusions are drawn:

(1) LPCSHTHSC concrete with the same design strength has superior mechanical properties than ordinary concrete [40].

(2) The water-binder ratio exerts the greatest impact on the compressive strength and splitting tensile strength of LPCSHTHSC concrete, and as the waterbinder ratio increases, the splitting tensile strength of concrete gradually lowers.

(3) The admixture amount of fly ash has a significant impact on the early compressive strength of LPCSHTHSC concrete, and with the increase of admixture, the compressive strength of concrete exhibits a downward trend.

(4) Under the same shale ceramsite admixture amount, water-reducing agent and water-binder ratio have a significant impact on the lightweight of LPCSHTHSC concrete. When the water-reducing agent admixture amount is $0.5 \%$ and the waterbinder ratio is 0.43 , there is the most obvious concrete lightweight.

(5) Through a comprehensive analysis of the compressive strength, splitting strength, apparent density, and economic indexes, the optimal proportion of LPCSHTHSC concrete was determined as follows: water-binder ratio 0.45 , sand ratio $35 \%$, water $210 \mathrm{~kg} / \mathrm{m}^{3}$, fly ash $20 \%$, silica fume $8 \%$, and waterreducing agent $0.5 \%$.

(6) By adding shale ceramsite, superplasticizer, and other admixtures into the concrete, each prefabricated composite slab can reduce weight by 
$74.78 \mathrm{~kg}$. Compared with ordinary concrete under the same design conditions [40], the apparent density of LPCSHTHSC concrete is reduced by $11.9 \%$, showing good weight reduction effect.

According to "Design Code for Concrete Structures" [28], single flexural loading test was performed on a piece of LPCSHTHSC, with a focus to study crack development in LPCSHTHSC, the ultimate bearing capacity of composite slab and the deflection changes of slab PC components. The following conclusions are drawn:

(1) The test cracking load of LPCSHTHSC relatively approaches the design cracking load, which shows that the existence of truss bars has little effect on the cracking load of the composite slab.

(2) The ultimate bearing capacity of LPCSHTHSC far exceeds the design bearing capacity, indicating that the mechanical properties of the lightweight composite slab meet the structural design requirements, and the performance is excellent [28].

(3) The ultimate bearing capacity of LPCSHTHSC calculated by the plastic hinge method has a small difference from the test value, so this method is applicable to solving the ultimate bearing capacity of LPCSHTHSC.

On the basis of the LPCSHTHSC static test, combining the experiments and simulations of existing scholars, we made analysis and comparison through finite element analysis software ABAQUS, and the following conclusions are drawn:

(1) The load-deflection curve obtained by ABAQUS finite element simulation is basically consistent with the test results, and deviations are acceptable.

(2) The ultimate bearing capacity of the traditional composite slab made of ordinary concrete is inferior to that of LPCSHTHSC, and the deflection increases fast.

(3) The finite element analysis results are relatively consistent with the actual failure characteristics, indicating that the concrete constitutive model and steel bar constitutive model [36] adopted herein are applicable. Moreover, the modified concrete plastic damage parameters based on the mechanical property test results of high-titanium heavy slag concrete are relatively accurate, so the concrete plastic damage model can be used to simulate the LPCSHTHSC cracking.

The research conclusions lay a theoretical and experimental basis for the lightweight of prefabricated building composite slabs.

The LPCSHTHSC PC component under research has obtained a Chinese invention patent, which facilitates its popularization and application in prefabricated buildings.

The research and development of this kind of green building materials [41] and its popularization and application in prefabricated buildings carry positive social and economic significances for comprehensive utilization of industrial solid waste of high-titanium heavy slag in civil engineering in Panxi, China, optimization and improvement of prefabricated composite slab PC components [42], building energy conservation, ecological environmental protection, and cost control in the upper reaches of the Yangtze River in China.

\section{Data Availability}

The data used to support the findings of this study are available from the corresponding author upon request.

\section{Conflicts of Interest}

The authors declare that there are no conflicts of interest regarding the publication of this paper.

\section{Acknowledgments}

This study was financially supported by PhD Starting Research Fund: Research on the Technology and Industry of a New Type of Prefabricated High-Titanium Heavy Slag Concrete Composite Board (no. 035200192).

\section{References}

[1] General Office of the State Council, "Guiding opinions of the general office of the state council on vigorous development of prefabricated buildings," Housing Industry, vol. 12, no. 10, pp. 24-26, 2016.

[2] China's Concrete and Cement, "Editorial department of "China concrete", major events of China's concrete and cement products industry in 2017," China Concrete, vol. 38, no. 1, pp. 18-20, 2018.

[3] Y. Yu, Y. Zhao, and Z. Gao, "Experimental study on flexural behavior of single-seam dense reinforced concrete composite slab," Journal of Building Structures, vol. 40, no. 4, pp. 29-37, 2019.

[4] W. Gaurav, K. Rajesh, S. N. Patel, and S. Singh, "Dynamic instability of trapezoidal composite plates under non-uniform compression using moving kriging based meshfree method," Thin-Walled Structures, vol. 164, Article ID 107766, 2021.

[5] J. Fan, J. Liu, J. Zhang, S. Yang, Z. Ai, and F. Chen, "Experimental study on negative bending moment behavior of composite plate beams using hybrid fiber ECC," Chinese Journal of Civil Engineering, vol. 54, no. 4, pp. 57-67, 201.

[6] L. S. Yousuf, "Nonlinear dynamics investigation of flexural stiffness of composite laminated plate under the effect of temperature and combined loading using Lyapunov exponent parameter," Composites Part B: Engineering, vol. 219, Article ID 108926, 2021.

[7] M. Zhou, Y. Zhang, S. Yang, C. Zhang, B. Zhang, and K. Zhang, "Study on flexural behavior of lightweight concrete composite slate with spontanized coal gangue sand," Journal of Building Materials, vol. 10, pp. 5-11, 2021.

[8] G. B. Valerio, P. Fanelli, and V. Francesco, "Ritz method analysis of rectilinear orthotropic composite circular plates undergoing in-plane bending and torsional moments," $\mathrm{Me}$ chanics of Advanced Materials and Structures, vol. 28, no. 9, 2021. 
[9] U. Arasan, F. Marchetti, F. Chevillotte, L. Jaouen, D. Chronopoulos, and E. Gourdon, "A simple equivalent plate model for dynamic bending stiffness of three-layer sandwich panels with shearing core," Journal of Sound and Vibration, vol. 500, Article ID 116025, 2021.

[10] K. Ege, N. B. Roozen, Q. Leclère, and R. G. Rinaldi, "Assessment of the apparent bending stiffness and damping of multilayer plates; modelling and experiment," Journal of Sound and Vibration, vol. 426, no. 3, pp. 129-149, 2018.

[11] N. D. Hai and H. Mutsuyoshi, "Structural behavior of doublelap joints of steel splice plates bolted/bonded to pultruded hybrid CFRP/GFRP laminates," Construction and Building Materials, vol. 30, pp. 347-359, 2012.

[12] X. Jiang and J. Yue, "Bearing capacities of ceramsite concrete composite slabs with trough bottom plate," Journal of Sichuan University (Engineering Science Edition), vol. 38, no. 6, pp. 6-12, 2006, in Chinese.

[13] J. Sun, "Fundamental research on a puplication of complex high titanium heavy slag concrete," Master dissertation, Chongqing University, Chongqing, China, 2006.

[14] S. Huang, W. Chen, and J. Sun, "Application of high titanium blast furnace slag in concrete materials," New Building Materials, vol. 32, no. 11, pp. 71-73, 2006.

[15] F. Xiao, Performance Research of Titanium Slag Concrete, Chongqing University, Chingqing, China, 2004.

[16] H. Jiang, Research and Application of High Titanium Heavy Slag Aggregate of High Performance concrete, Wuhan University of Technology, Wuhan, China, 2011.

[17] J. Sun, W. Chen, Y. Li, and W. Zhou, "Experiment and analysis of bond properties between complex high titanium heavy slag concrete (CHTHSC) and reinforcement," Sichuan Building Science, vol. 35, no. 4, pp. 216-219, 2010.

[18] X. Li, W. Chen, and X. Li, "Experimental study on seismic performance of high strength concrete columns with high titanium heavy slag as coarse and fine aggregates," Building Structure, vol. 42, no. 9, pp. 96-100, 2013.

[19] W. Chen, S. Huang, J. Sun, and T. Jiao, "Experimental research on the normal section strength of high titanium heavy slag reinforced concrete beams," Sichuan Building Science, vol. 34 , no. $4,2009$.

[20] W. Huang, B. Luo, B. Li, X. Xu, and Y. Su, "Experimental study on flexural behavior of green concrete composite slabs with different structural forms," Journal of Hunan University (Natural Science), vol. 46, no. 7, pp. 35-44, 2019.

[21] H. Huang, Mechanical Performance and Design Method of Precast Ribbed Concrete Composite Floor Slab, Hunan University, Changsha, China, 2013.

[22] Y Ren and P. Xu, "Study on failure mode of composite floor slate based on finite element analysis of damage model," Industrial Construction Magazine, vol. 5, 2020.

[23] Z. Yu, "Questioning, government environmental subsidies and environmental protection green innovation," Foreign Economics \& Management, vol. 43, pp. 1-16, 2021.

[24] China Academy of Building, Design Regulations for Proportioning of Common Concrete, China Architecture \& Building Press, Bejing, China, 1997.

[25] R. Liu, Y. Zhang, and C. Wen, "Study on the design and analysis methods of orthogonal experiment," Experimental Technology and Management, vol. 27, no. 9, pp. 52-55, 2010.

[26] L. Hao, X. Zhang, and L. Liu, "Analysis method of results in orthogonal design in scientific papers," Acta Editologica, vol. 19 , no. 5, pp. 340-341, 2007.
[27] C. Architecture and B. Press, Standard for Test Methods of Concrete Structures, China Architecture \& Building Press, Bejing, China, 1992.

[28] J. Zhao, Y. Xu, and X. Huang, "Code for design of concrete structures (GB 50010-2010)," Construction Science and Technology, vol. 13, no. 10, pp. 28-30, 2015.

[29] S. Chen, Experiment and Analysis of PK Prestressed Concrete Composite Slab on Simple Support, Hunan University, Hunan, China, 2012.

[30] A. Ingerslev, The Strength of Rectangular Slabs, Insituation Structural Engineers, London, UK, 1923.

[31] K. W. Johnson, "Publisher's announcement yield-line theory," Magazine of Concrete Research, vol. 14, no. 40, p. 54, 1962.

[32] K. W. Johansen, Yield-Line Formulae for Slabs, CRC Press, Boca Raton, FL, USA, 1972.

[33] J. Shen and C. Wang, Architecture, etc, Limit Analysis of Reinforced Concrete Finite Element Plate and Shell, Tsinghua University Press, Bejing, China, 1993.

[34] F. Wu, H. Huang, and W. Chen, "Ultimate bearing capacity of concrete two-way composite slabs with precast concrete ribbed panels," Journal of Civil,Architectural \& Environmental Engineering, vol. 54, no. 5, pp. 34-40, 2011.

[35] X. Lv, Nonlinear Finite Element Theory and Application of Reinforced Concrete Structure, Tongji University Press, Shangai, China, 1996.

[36] X. Ma, Study on Mechanical Behaviors of Reinforced Concrete Superimposed Slabs with Steel Bar Truss, Southeast University, Dhaka, Bangladesh, 2017.

[37] J. Liu and H. Liu, "ABAQUS finite element analysis of reinforced concrete," Equipment Manufacturing Technology, vol. 15, no. 6, pp. 69-70, 2009.

[38] F. Qin, Y. Huan, Y. Zhang, and L. Chen, "Investigation into static properties of damaged plasticity model for concrete in ABAQUS," Journal of PLA University of Science and Technology (Natural Science Edition), vol. 22, no. 3, pp. 254-260, 2007.

[39] B. Sun, D. Ding, S. Zeng, and J. Shi, "Numerical analysis of two-stage loading progresses on reinforced concrete composite structures," Journal of Huazhong University of Science and Technology (Urban Science Edition), vol. 25, no. 4, pp. 260-263, 2008.

[40] B. Qian, J. Hu, M. Qi, F. Zheng, and J. Zhao, "Experimental research on performance of C30 concrete with aggregate of high titanium heavy slag in xichang city," Bulletin of the Chinese Ceramic Society, vol. 37, no. 6, pp. 2062-2066, 2018.

[41] Panzhihua Municipal Committee's, CPC Panzhihua Municipal Committee's Proposal on Formulating the 14th Five-Year Plan for National Economic and Social Development of Panzhihua City and the Long-Term Goals in 2035, Panzhihua Daily, Sichun, China, 2021.

[42] O. Liu, The Optimal Selecti on of Different Concrete Floors in Assembly Building, Liaocheng University, Liacheng, China, 2017. 